\title{
ANÁLISIS DE LA METODOLOGÍA UTILIZADA EN LA BÚSQUEDA DE «LO QUE EL ALUMNO SABE» SOBRE FUERZA
}

\author{
SOLANO, ISABEL ${ }^{1}$, JIMÉNEZ-GÓMEZ, ENRIQUE ${ }^{1}$ y MARÍN, NICOLÁS ${ }^{2}$ \\ ${ }^{1}$ Departamento de Didáctica de las Ciencias Experimentales. Universidad de Murcia. \\ ${ }^{2}$ Departamento de Didáctica. Universidad de Almería.
}

\section{SUMMARY}

In a previous paper we compared research carried out in the decade 75-85 on students' conceptions of «force» with later research in the period 85-95. Only a slight progression was found in the results offered by different authors. The aim of the present paper is to analyse the reasons for this lack of progress in the research results, as regards the appearance of conceptions. To the end we have analysed the research objectives of the selected papers, their methodological characteristics and their most widely used theoretical foundations.

\section{INTRODUCCIÓN}

Las revisiones realizadas por Carmichael y otros (1990), Confrey (1990), Hierrezuelo y Montero (1989), entre otros, ofrecen una extensa y amplia información acerca de las concepciones que tienen los alumnos sobre los diferentes tópicos de ciencias. La gran cantidad de información de la cual hoy se dispone hace pensar que ésta es una línea de investigación prácticamente agotada. Sin embargo, en los últimos años han aparecido diferentes trabajos, tales como los realizados por Moreira (1994), Duschl (1994), Gilbert (1995), Sanmartí y Azcárate (1997), entre otros, en los que se reflexiona sobre las carencias metodológicas y la ausencia de un contexto teórico en los estudios descriptivos realizados sobre concepciones.

Conocer si ha existido progresión, en cuanto a resultados, metodología y contexto teórico en los estudios realizados sobre las concepciones de los alumnos, desde el punto de vista empírico, resulta imprescindible para orientar las investigaciones que tengan como objetivo determinar lo que «sabe» el alumno acerca de un determinado contenido y, obviamente, las implicaciones que tienen tales estudios en la enseñanza y en el aprendizaje.

Para estudiar si ha existido evolución en las investigaciones sobre concepciones, en cuanto a resultados, en Jiménez-Gómez, Solano y Marín (1997) se realizó un primer trabajo, en el cual se comparaba el catálogo de concepciones que tienen los alumnos sobre los conceptos básicos de la dinámica, publicados en la década 1975-85 con los publicados en la de 1985-95. Allí se puso de manifiesto que la primera década fue mucho más rica que la segunda. Por ejemplo, en la segunda década sólo se realizaron ratificaciones o matizaciones de concepciones previamente obtenidas, sin que prácticamente surgieran otras nuevas. Aquí, en este trabajo, se pretende analizar la metodología utilizada para investigar las concepciones que tienen los alumnos sobre fuerza, con 
el fin de encontrar las causas que expliquen la falta de progresión de este tipo de estudios. Para ello se analiza:

a) lo que los autores buscan en sus investigaciones, desde el punto de vista de objetivos;

b) los términos utilizados en este tipo de trabajos y los significados a los que van asociados;

c) las características metodológicas (técnicas de recogida de datos: manera de agruparlos, categorizarlos e interpretarlos);

d) los marcos teóricos que con mayor frecuencia son utilizados.

\section{SELECCIÓN DE TRABAJOS PUBLICADOS}

\section{Selección del contenido}

Se eligió mecánica por ser uno de los tópicos en los que las concepciones de los alumnos han sido más estudiadas (Moreira, 1994). Sin embargo, resultó excesivo el número de artículos encontrados, por lo que se volvió a delimitar el contenido a los principios de la dinámica. De esta manera, la fuerza, los principios y leyes con ella relacionados constituyen el contenido académico objeto de la investigación.

\section{Elección de una muestra representativa de los traba- jos publicados}

Otro problema ha sido la selección de una muestra de trabajos representativos de la investigación realizada sobre concepciones de los alumnos relacionadas con el concepto de fuerza (Jiménez-Gómez, Solano y Marín, 1997). Una dificultad añadida es que la mayoría de los trabajos están publicados en actas de congresos, reuniones o encuentros que son difíciles de obtener. De ahí que se optara por seleccionar sólo aquéllos que hubiesen sido publicados en revistas del ámbito exclusivo de la enseñanza de las ciencias. Aun así, su número fue muy elevado, por lo que se seleccionaron las siguientes revistas, que resultaron accesibles para nosotros y además porque cubren el objetivo del trabajo: Enseñanza de las Ciencias (desde sus comienzos en 1983 a 1995), European Journal of Science Education (hoy: International Journal of Science Education, 1979-95; el primer número que se ha conseguido es del año 1979), Physics Education (1975-95) y Science Education (1975-95).

Una vez seleccionadas las revistas, se fijó el período de revisión de publicaciones desde 1979, año en que aparece el trabajo de Viennot, hasta el momento actual. Se han excluido aquellas publicaciones de índole exclusivamente teórica, aunque hiciesen en algún momento referencia a las «concepciones» de los alumnos sobre el concepto de fuerza, pero que no ofreciesen propuestas metodológicas ni resultados. En total se seleccionaron 29 artículos.

\section{CLASIFICACIÓN DE LOS TRABAJOS SE- LECCIONADOS}

Al encontrar una gran diversidad de objetivos a conseguir en los diferentes trabajos seleccionados, se aplicó un criterio de clasificación empírico (Jiménez-Gómez, Solano y Marín, 1997), basado en considerar trabajos en los cuales:

1) La clasificación de las respuestas está ligada a las peculiaridades de los hechos físicos presentados en el cuestionario utilizado para estudiar las respuestas de los alumnos; a este grupo de trabajos los hemos denominado descriptivos dependientes de los hechos físicos, y con estos términos se hará referencia más adelante.

2) Se establecen agrupaciones sobre respuestas que dan los alumnos a preguntas sobre distintas situaciones físicas, en las que subyace un mismo contenido de enseñan$\mathrm{za}$, de modo que las conclusiones pertenecen a un plano

Tabla I

Distribución por categorías de los trabajos seleccionados.

\begin{tabular}{|l|l|l|}
\hline Descriptivos dependientes & Descriptivos independientes & Descriptivos relacionales \\
\hline Helm, 1980; Gunstone y White, 1981; & Viennot, 1979; Watts y Zylbersztajn, 1981; & Selman y otros, 1982; Bar, 1989; \\
Ivowi, 1984; Terry y Jones, 1986; & Watts, 1982; Watts, 1983; Maloney, 1984; & Acevedo y otros, 1989 \\
Clement y otros, 1989; Brown, 1989; & Ruggiero y otros, 1985; Terry y otros, 1985; & \\
Kruger y otros, 1992; Galili, 1993 & Noce y otros, 1988; Boeha, 1990; \\
& Villani y Pacca, 1990; Finegold y Gorsky, 1991; & \\
& Thijs, 1992; Galili y Bar, 1992; Reynoso y otros, & \\
& 1993; Bar y otros, 1994; Twigger & \\
& y otros, 1994; Kuiper y Mondlane, 1994; & \\
& Montanero y Pérez, 1995 & \\
& & \\
\hline
\end{tabular}


de generalidad claramente superior al plano de los hechos implicados en el cuestionario. Nos referiremos a los trabajos que están dentro de esta categoría con los términos descriptivos independientes de los hechos físicos.

3) Se establecen relaciones entre las categorías realizadas sobre las respuestas de los alumnos con variables que han mostrado ser relevantes para determinar las capacidades cognitivas del sujeto, como es el caso de la memoria a corto o largo plazo, las operaciones mentales, etc. A estos trabajos, los denominaremos descriptivos relacionales, en cuanto que no establecen sus relaciones con otros factores cognitivos utilizando el contexto teórico en el que fueron establecidos dichos factores, sino sólo utilizando técnicas estadísticas descriptivas.

En la tabla I se presentan las tres categorías establecidas en las que se distribuyen todos los trabajos de dinámica seleccionados.

Esta clasificación permite homogeneizar y comparar, de modo más eficiente, los diferentes artículos que están clasificados dentro del mismo grupo.

Para hacer el análisis de la metodología utilizada en las investigaciones referidas a las concepciones de los alumnos sobre fuerza, se han elegido los trabajos clasificados como independientes de los hechos físicos, por ser el grupo más representativo (18 artículos) y más numeroso.

\section{ANÁLISIS DE LOS ASPECTOS METODOLÓGI- COS UTILIZADOS EN LOS TRABAJOS INDE- PENDIENTES DE LOS HECHOS FÍSICOS}

El análisis de las características metodológicas se inicia con el estudio descriptivo de los objetivos de los 18 trabajos seleccionados, los términos y los significados asociados a éstos; a continuación, se hace una revisión de las técnicas de recogida de datos y, por último, se analizan las distintas maneras de tabular, presentar y categorizar las respuestas de los alumnos, así como los diferentes marcos teóricos utilizados.

\section{¿Qué buscan los investigadores en sus investigacio- nes?}

Seleccionados los trabajos clasificados como independientes de los hechos físicos presentados, se trata de describir, a partir del anexo I, los objetivos básicos que los investigadores intentan alcanzar en sus trabajos. Se ha encontrado los que:

a) Identifican y describen concepciones deducidas de las respuestas de los sujetos (Watts, 1982 y 1983; Ruggiero et al., 1985; Terry et al., 1985; Reynoso et al., 1993; Twigger et al., 1994; Villani y Pacca, 1990) o intentan inferir reglas, modelos, leyes, etc., por las que se rigen sus explicaciones (Viennot, 1979; Maloney, 1984; Montanero y Pérez, 1995). b) Comprueban si las concepciones obtenidas por otros autores eran compartidas por otras muestras de alumnos (Watts y Zylbersztajn, 1981; Noce et al., 1988).

c) Buscan analogías entre las concepciones de los alumnos y el desarrollo histórico de la dinámica (Galili y Bar, 1992), enfatizando de manera especial las ideas de Aristóteles (Boeha, 1990).

d) Estudian la consistencia y coherencia de las concepciones (Finegold y Gorsky, 1991; Kuiper y Mondlane, 1994; Viennot, 1979; Montanero y Pérez 1995).

e) Analizan la dependencia de las concepciones con la edad o con el grado de instrucción (Noce et al., 1988; Galili y Bar, 1992; Twigger et al., 1994; Kuiper y Mondlane, 1994; Bar et al., 1994).

Cabe señalar, con respecto a la anterior clasificación, que el hecho de que un trabajo esté presente en dos o más apartados diferentes se debe a que sus autores, explícitamente, proponen alcanzar cada uno de los objetivos referidos en dichos apartados.

La clasificación realizada pone de manifiesto que los objetivos relativos a la identificación y descripción de las concepciones se encuentran de igual manera representados a lo largo de los años (objetivos $a$ y $b$ ). Sin embargo, también aparecen otros nuevos, como son la búsqueda de analogías entre las concepciones de los alumnos y el desarrollo histórico del concepto de fuerza (objetivo $c$ ), estudios de consistencia (objetivo $d$, a excepción de Viennot, que lo realiza en la década anterior) y la dependencia de las concepciones con la edad o con el grado de instrucción (objetivo $e$ ).

Aunque existen nuevos objetivos a conseguir en los estudios de concepciones realizados a lo largo de los años, no ocurre igual con la terminología utilizada en la muestra de artículos seleccionados, en la que aparecen 32 términos diferentes cuando los investigadores se refieren a «lo que sabe» el alumno sobre fuerza. Resultados análogos se exponen, cuando este análisis se hace para éste u otros conceptos, en Abimbola (1988), Millar (1989), Giordan y Vechi (1987), Jiménez-Gómez, Solano y Marín (1994), entre otros.

De los 32 términos, los más utilizados han sido el de esquema (utilizado por 9 de los 18 trabajos analizados), seguido por el de concepción (6 de los 18), por lo que se pasa a describir sus significados.

Según el contexto y el empleo del término esquema, los significados que se le han asociado son:

- Un conjunto de conceptos comunes y coherentes consigo mismos (esquema explicativo de física intuitiva, Viennot, 1979).

- Una conceptualización personal o ideas de los alumnos coherentes con sus experiencias sobre el entorno natural (esquema alternativo, Watts y Zylbersztajn, 1981; Watts, 1982; Terry et al., 1985). 
- Un esfuerzo imaginativo de una persona para describir y explicar su mundo físico (esquema alternativo, Watts, 1982).

- Una descripción de una perspectiva desde la cual pueden predecirse las respuestas de los alumnos a distintas cuestiones; una creencia o conjunto de creencias que el alumno aplica consistentemente a distintas situaciones físicas (esquema alternativo, Finegold y Gorsky, 1991).

- Un conjunto de ideas consistentes entre sí, relativas a un mismo concepto puesto en juego en diferentes áreas problemáticas y contextos (esquema alternativo, Kuiper y Mondlane, 1994).

- Una red de relaciones que constituye el conocimiento de hechos y fenómenos usados por un niño o cualquier persona, que se corresponde con la experiencia y tiene poder de predicción (esquema de comprensión, de interpretación o de conocimiento espontáneo [Ruggiero et al., 1985], esquemas explicativos alternativos o de conocimiento de sentido común [Noce et al., 1988], esquemas alternativos [Reynoso et al., 1993]).

En cuanto al término concepción, los significados encontrados han sido:

- Categorías de respuesta: modelos descriptivos (respuestas que describen el comportamiento de los objetos) o explicativos (respuestas en las que aparece un conjunto consistente de relaciones entre nociones y hechos), (concepciones o creencias [Noce et al., 1988]).

- Significados construidos por el individuo para dar sentido al mundo y que constituyen malas interpretaciones de situaciones físicas (concepciones erróneas [Thijs, 1992]).

- Ideas de los alumnos extraídas de las respuestas erróneas de los sujetos cuando se les plantea una situación física. Algunas reflejan analogías con la historia de la ciencia (concepciones erróneas [Galili y Bar, 1992]).

- Conceptualizaciones de los estudiantes, deducidas por el investigador, a partir de las descripciones y explicaciones de los mismos (concepciones previas [Twigger et al., 1994]).

- Descripciones de las explicaciones de los alumnos sobre un cierto hecho físico (concepciones espontáneas [Montanero y Pérez, 1995]).

Se observa que diferentes autores emplean términos distintos para referirse a lo mismo, como parece deducirse de lo expresado por autores como Boeha (1990): «A los puntos de vista de los estudiantes se les ha dado una variedad de nombres tales como concepciones ingenuas, creencias ingenuas, formas espontáneas de razonamiento, inventarios conceptuales, conocimiento ingenuo, física intuitiva, errores conceptuales, esquemas alternativos, creencias de los estudiantes, etc.» Esto es cierto en algunos casos. Así, Viennot (1979) se refiere a una ley intuitiva que puede expresarse como una relación pseudolineal entre fuerza y velocidad, Watts (1983) habla del esquema alternativo según el cual las fuerzas son requeridas para causar y mantener el movimiento y Galili y Bar (1992) se refieren a la creencia de que movimiento implica fuerza.

La diversidad de términos utilizados y significados asociados es un índice más del escaso consenso que existe entre los investigadores para referirse a «lo que el alumno sabe» sobre el contenido objeto de enseñanza. No se observa abandono de términos y asunción de otros. Por otro lado, la asignación de significados al término esque$m a$, de uso más frecuente, se utiliza por igual en ambas décadas.

La extensa variedad de vocablos para referirse a «lo que el alumno sabe» explica o deja entrever las dificultades a la hora de comparar, desde un punto de vista metodológico, los diferentes artículos seleccionados, a pesar de haber seleccionado sólo los relativos al agrupamiento: «trabajos independientes de los hechos físicos».

\section{Recogida de datos y construcción del cuestionario}

En el anexo II se presentan: en la primera columna, los autores; en la segunda y tercera, la técnica utilizada para la recogida de datos; en la cuarta, las características más sobresalientes del cuestionario en cuanto a la manera como ha sido construido; y, por último, en la quinta, la muestra utilizada en las diferentes investigaciones.

Se observa, en el citado anexo, una gran variedad de técnicas utilizadas para la recogida de datos, bien por la técnica en sí o por las combinaciones posibles que se pueden establecer entre ellas. Se han encontrado:

1) Preguntas abiertas de lápiz y papel sobre situaciones físicas presentadas (Viennot, 1979; Ruggiero et al., 1985; Noce et al., 1988; Finegold y Gorsky, 1991; Galili y Bar, 1992; Reynoso et al., 1993; Kuiper y Mondlane, 1994).

2) Test de elección múltiple en el que generalmente también se solicita del alumno una explicación sobre la opción elegida (Watts y Zylberztajn, 1981; Ruggieroet al., 1985; Thijs, 1992; Kuiper y Mondlane, 1994; Montanero y Pérez, 1995).

3) Varias técnicas de entrevista individual o por parejas:

a) Entrevista sobre ejemplos (dibujos lineales [Watts, 1982 y 1983; Boeha, 1990] o utilizando fotografías (Noce et al., 1988). En este caso se utiliza una colección de tarjetas que contienen dibujos y se pide al sujeto interpretarlos como ejemplos o no de su concepto de fuerza; también se le pregunta sobre las razones que le llevan a dar esa respuesta.

b) Entrevista personal (Finegold y Gorsky, 1991; Reynoso et al., 1993; Montanero y Pérez, 1995). Generalmente se pide al sujeto que dé explicaciones sobre 
alguna cuestión que se le propone o sobre un cuestionario que cumplimentó anteriormente en la entrevista.

c) Entrevista por parejas (Twigger et al., 1994). Se centra en un suceso particular, el cual se muestra directamente o se presenta mediante un vídeo o dibujos y se lleva a cabo entre parejas para estimular el debate. Sin embargo, cada sujeto escribe o dibuja la respuesta sobre su propio papel.

Se pone de manifiesto que algunos trabajos suelen emplear una mezcla de, al menos, dos técnicas de recogida de información: preguntas abiertas de lápiz y papel y test de elección múltiple con explicación (Ruggiero et al., 1985; Kuiper y Mondlane, 1994), preguntas abiertas de lápiz y papel y entrevista personal (Reynoso et al., 1993) o test de elección múltiple con explicación y entrevista personal (Montanero y Pérez, 1995) y, en el caso de utilizar test de elección múltiple, éste suele ir acompañado de la petición de una explicación de la opción seleccionada (Watts y Zylberztajn, 1981; Thijs, 1992).

Algunos autores se deciden por una técnica u otra en función de la edad de los sujetos que constituyen la muestra. Así, Reynoso y otros (1993) o Noce y otros (1988) utilizan preguntas abiertas de lápiz y papel y entrevista personal o sólo esta última, en función de que los estudiantes sean de secundaria o de primaria.

Respecto a la construcción del cuestionario o protocolo para la recogida de datos, hemos encontrado diferencias en cuanto a:

\section{1) Las preguntas:}

a) La mayoría de los autores realizan preguntas en las que se hace intervenir el significante del contenido de enseñanza, el cual es objeto de búsqueda. Por ejemplo, preguntas directas del tipo «¿Qué fuerza actúa sobre...?» son utilizadas por Viennot (1979), Watts y Zylberztajn (1981), Watts (1982 y 1983), Ruggiero y otros (1985), Noce y otros (1988), Boeha (1990), Finegold y Gorsky (1991), Thijs (1992), Galili y Bar (1992), Twigger y otros (1994), Kuiper y Mondlane (1995), Montanero y Pérez (1995).

b) Algunos autores hacen preguntas a los sujetos sobre definiciones de términos (Ruggiero et al., 1985; Noce et al., 1988; Reynoso et al., 1993; Twigger et al., 1994).

c) En todos los trabajos se solicita algún tipo de explicación, una vez que los sujetos han contestado algunas preguntas, por ejemplo, a una prueba de lápiz y papel.

2) La técnica de recogida de datos:

a) Se solicitan predicciones a los alumnos (Viennot, 1979; Ruggiero et al., 1985; Noce et al., 1988; Reynoso et al., 1993; Twigger et al., 1994; Kuiper y Mondlane, 1994).

b) Los alumnos además de predecir deben comprobar su predicción (Twigger et al., 1994). c) Se solicitan gráficas (Twigger et al., 1994).

d) Se construye el cuestionario utilizando la técnica de «valoración de reglas» de Siegler (Maloney, 1984).

Por otro lado, 11 de los 18 trabajos seleccionados utilizan alguna cuestión o situación física sacada de otras investigaciones realizadas con anterioridad: Watts y Zylberztajn (1981), Watts (1982 y 1983), Ruggiero y otros (1985), Noce y otros (1988), Boeha (1990), Finegold y Gorsky (1991), Galili y Bar (1992), Reynoso y otros (1993), Twigger y otros (1994), Kuiper y Mondlane (1995).

Tres trabajos expresan, de manera explícita, que han realizado estudios preliminares para ajustar el formato del cuestionario definitivo: Ruggiero y otros (1985), Thijs (1992), Montanero y Pérez (1995).

El análisis de la construcción del cuestionario indica:

a) Existe coincidencia, por parte de la mayoría de los investigadores de ambas décadas, en realizar preguntas directas del tipo «¿Qué fuerza actúa sobre...?» ante un hecho físico real o un dibujo sacado de la realidad.

b) No existe coincidencia en la forma de elaborar los cuestionarios. Así, sólo en un trabajo se solicita que los alumnos entrevistados comprueben sus predicciones sobre un hecho físico; en otro, se realizan gráficos; en 3 de los 18 trabajos analizados, se realizan estudios preliminares para ajustar el cuestionario definitivo; y 11 utilizan cuestiones o situaciones físicas sacadas de investigaciones anteriores.

\section{Presentación, tabulación y categorización de los datos}

Los datos que se han entresacado y que se consideran más relevantes, en cuanto a la ordenación y categorización de las respuestas de los alumnos, se presentan en el anexo III. En la primera columna se recogen los autores; en la segunda, el tipo de agrupamiento de las respuestas $\mathrm{y}$, en las columnas restantes, las características de las categorías realizadas por los diferentes investigadores.

Aunque la mayor parte de los trabajos recogen, a modo de ejemplo, algunos fragmentos de respuestas concretas de los alumnos (13 de 18), todos ellos realizan descripciones de dichas respuestas, de ahí que exista cierto grado de interpretación, por lo que se ha procedido a realizar una clasificación en base a los modos en que los distintos autores proceden a agrupar las respuestas para su categorización. Así, se encuentran trabajos en los que:

a) Las categorías establecidas recogen principalmente aquellas respuestas que el autor considera relevantes por tratarse de:

- respuestas erróneas más frecuentes (Viennot, 1979; Watts 1982, 1983; Thijs, 1992; Twigger et al., 1994); 
- opciones no correctas en un test de elección múltiple (Watts y Zylbersztajn, 1981);

- tener una consistencia o coherencia en el conjunto de respuestas dadas por cada alumno (Finegold y Gorsky, 1991; Kuiper y Mondlane, 1994; Montanero y Pérez, 1995);

- respuestas que parecen reflejar opiniones sostenidas a lo largo de la historia de la ciencia (Boeha, 1990; Galili y Bar, 1992);

- las categorías mayoritarias que se pretenden utilizar para un estudio longitudinal (Bar et al., 1994).

b) Las categorías recogen todo el conjunto de respuestas, de modo que las correctas o cercanas a las correctas constituyen un grupo categorial más (Ruggiero et al., 1985; Noce et al., 1988; Reynoso et al., 1993).

Esta primera clasificación, fundamentalmente descriptiva, pone de manifiesto que las categorías están configuradas sobre la base del propio contenido académico que es objeto de investigación. Este hecho resulta de gran importancia porque viene a indicar que las respuestas de los sujetos son descritas, la mayoría de las veces, desde los conocimientos del investigador, como experto, es decir, se buscan las distancias que pueden existir entre el novato y el experto.

Respecto a la manera de establecer las relaciones entre las diferentes categorías, se ha encontrado que:

a) No se percibe un intento de establecer relaciones entre los distintos grupos categoriales (Watts y Zylbersztajn, 1981; Watts, 1982 y 1983; Terry et al., 1985; Villani y Pacca, 1990; Finegold y Gorsky, 1991; Thijs, 1992; Twigger et al., 1994; Montanero y Pérez, 1995).

b) Aparece cierta relación entre tipos de respuestas entresacadas de las distintas cuestiones por presentar analogías con las encontradas a lo largo de la historia de la ciencia (Boeha, 1990; Galili y Bar, 1992).

c) Se establecen relaciones entre las distintas categorías, intentado establecer una cierta jerarquización entre ellas, la cual puede estar basada en:

- criterios obtenidos del análisis de la estructura lógica o semántica de los conceptos que son objeto de investigación (Viennot, 1979; Maloney, 1984; Ruggiero et al., 1985; Noce et al., 1988);

- el grado de complejidad en la respuesta (Bar et al., 1994);

- la «distancia» (correctas-intermedias-intuitivas) con el contenido académico (Kuiper y Mondlane, 1994).

La progresión en cuanto al establecimiento de categorías, si la hubiera, se debe más a los objetivos planteados por los investigadores que a un evidente cambio metodológico en el que se abandonen unas formas de categorizar datos y se propongan y acepten otras.

Respecto de los trabajos que intentan establecer relaciones entre categorías, no se observa una tendencia clara. Tampoco se observa homogeneidad a la hora de hacer una descripción estadística de los datos en estudios cuantitativos. En cualquier caso, en la tabulación y categorización de las respuestas de los alumnos interviene, de manera considerable, el marco teórico utilizado que, como se ha comentado anteriormente, suele estar basado en la propia ciencia; y dicho marco teórico, a su vez, determina el tipo de metodología que se utiliza en el trabajo. Por esta razón se procede a su análisis en el siguiente apartado.

\section{Descripción de los resultados y secuencia de investi- gación}

En el anexo IV se presenta: $a$ ) en la primera columna, los autores que forman la muestra; $b$ ) en la segunda, los supuestos de partida hechos explícitos por el investigador; y $c$ ) en la tercera, el tipo de metodología utilizada (inductiva, hipotético-deductiva, etc.), deducido a partir de la lectura de los trabajos.

En el análisis de las diferentes fases prácticas de la investigación (diseño, construcción del cuestionario, clasificación de las respuestas de los alumnos) todas analizadas en los epígrafes anteriores, se ponía de manifiesto que el contexto teórico que subyace en la mayoría de los trabajos está basado en el propio contenido académico. Ahora se trata de describir las distintas formas que tienen los sujetos de concebir el mundo que les rodea, desde la perspectiva que supone la interpretación que hace cada uno de los investigadores de las respuestas de los alumnos. De ahí, que dichas respuestas sean descritas en los diferentes trabajos analizados como:

1) Coherentes y, por tanto, los investigadores:

a) Dan por sentado que todos los individuos realizan conceptualizaciones personales del mundo que les rodea a partir de sus experiencias, y representan una forma distinta de comprender acontecimientos cotidianos a como lo hace la ciencia, y tienen carácter de predicción (Viennot, 1979; Watts y Zylberstajn, 1981; Watts, 1982 y 1983; Maloney, 1984; Terry et al., 1985; Villani y Pacca, 1990; Bar et al., 1994; Montanero y Pérez, 1995).

b) Parten del supuesto de que el conocimiento de hechos y fenómenos por parte de un niño o cualquier persona sin competencia específica en un campo está organizado en redes de relaciones y tiene poder de predicción (Ruggiero et al., 1985; Noce et al., 1988; Reynoso et al., 1993).

c) Suponen que existe cierto paralelismo entre las concepciones sostenidas a lo largo de la historia de la ciencia y la formación del conocimiento en el alumno, de forma que se utiliza la historia para buscar analogías con las respuestas de los alumnos (Boeha, 1990; Galili y Bar, 1992). 
e) Se alinean explícitamente en la corriente del cambio conceptual (Thijs, 1992; Twigger et al., 1994).

2) Incoherentes y, por tanto, los investigadores:

a) Admiten que las respuestas de los sujetos no tienen que ser reflejo de un conocimiento coherente (Finegold y Gorsky, 1991; Kuiper y Mondlane, 1994).

b) Aceptan que detrás de respuestas correctas puede haber un razonamiento incorrecto (Galili y Bar, 1992).

El que unos autores consideren las respuestas de los alumnos coherentes y otros incoherentes se debe fundamentalmente, según nuestro criterio, a:

1)Las diferentes estrategias metodológicas utilizadas por los diferentes investigadores. Por ejemplo, Finegold y Gorsky (1991) llegan a la conclusión de que los resultados de su investigación contradicen los de Viennot (1979) y Watts (1983), a pesar de que inicialmente proponen, en sus trabajos, análogos objetivos. La razones, a nuestro modo de entender, pueden encontrase en que Viennot y Watts, en sus cuestionarios presentan a los alumnos situaciones únicas; en cambio Finegold y Gorsky emplean situaciones físicas diferentes para investigar igual contenido, lo que les lleva a la conclusión siguiente: existen tantos modelos como estudiantes, por lo que la información que se obtiene de los diferentes estudiantes no tiene utilidad didáctica.

2) Lo que realmente buscan los investigadores en las respuestas de los sujetos. Por ejemplo, Maloney (1984) intenta establecer reglas, modelos, leyes, etc. que rigen las explicaciones de los alumnos; Bohea (1990) busca analogías entre las respuestas de los alumnos y las concepciones sostenidas a lo largo de la historia de las ciencias, de ahí que estos autores encuentren cierta coherencia en dichas respuestas

3) Que los investigadores, a veces, no tienen en cuenta:

a) Que existen términos que algunos sujetos sólo diferencian desde el punto de vista de significantes, pero no de significados. Por ejemplo, si se pregunta a un sujeto de 12 años por qué Juan puede arrastrar un saco de patatas, contestará: «porque tiene fuerza». Otras veces «porque tiene energía». Para él, los términos fuerza y energía están indiferenciados, como significados pero no como significantes.

b) El nivel de conceptualización que puede darse en un concepto. Por ejemplo, si se pregunta a un niño pequeño qué es la fuerza, posiblemente enseñará los músculos que tiene. Entre esta respuesta y esta otra, «variación infinitesimal posicional de la energía, cuya orientación la adquiere de la variación infinitesimal de la posición y el módulo de la variación infinitesimal de la energía», no cabe duda de que existe toda una serie de niveles o grados de conceptualización, cuya descripción es de gran utilidad didáctica, pero que, si no se tienen en cuenta, y además se producen interferencias con los significantes, puede hacer que algunos investigadores encuentren tantas respuestas diferentes como sujetos entrevistados.

En cuanto al tipo de metodología, encontramos que existen trabajos tanto inductivos (Viennot, 1979; Watts, 1982; Watts, 1983; Terry et al., 1985; Villani y Pacca, 1990; Thijs, 1992; Reynoso et al., 1993; Twigger et al., 1994) como hipotético-deductivos (Maloney, 1984; Ruggiero et al., 1985; Noce et al., 1988; Boeha, 1990; Finegold y Gorsky, 1991; Bar et al., 1994; Kuiper y Mondlane, 1994; Montanero y Pérez, 1995) a lo largo de los años, si bien no se observa, de manera evidente, que exista un abandono de la metodología inductiva en favor de la hipotético-deductiva, ni al contrario. No obstante, sí ha aumentado el número de trabajos hipotético-deductivos en los últimos años.

\section{CONCLUSIONES}

Del análisis comparativo realizado anteriormente, se pueden extraer las siguiente conclusiones:

a) Los objetivos de la mayoría de los trabajos realizados en los últimos años han estado dirigidos fundamentalmente a comprobar si las concepciones obtenidas en trabajos anteriores eran compartidas por otras muestras de alumnos, a estudiar su consistencia y coherencia, y a analizar su dependencia con la edad o grado de instrucción de los sujetos.

b) Se observa un elevado número de términos utilizados para referirse a «lo que sabe» el alumno. No se detecta una tendencia encaminada al abandono o la aceptación de alguno de ellos. El término esquema asociado a otro (explicativo, alternativo, de comprensión, etc.) es el más utilizado; le sigue el término concepción.

c) Los significados que se asocian a los términos esquema y concepción son múltiples y variados, de ahí que se pueda decir que no existe consenso alguno en asignar un único significado a cada uno de los términos e, incluso, algunos autores utilizan ambos términos para referirse a lo mismo.

d) Respecto a las técnicas utilizadas para la recogida de datos, no se han podido encontrar regularidades (salvo que la mayoría son pruebas de papel y lápiz), ya que los procedimientos utilizados en el diseño y construcción de los cuestionarios y las combinaciones de las mismas, difieren de unos trabajos a otros. No obstante, el tipo de técnica empleada viene determinada por las características de la muestra que se utiliza (número de sujetos o rango de edades).

e) Existe cierta convergencia a la hora de construir la mayor parte del cuestionario en cuanto a utilizar preguntas en las que se implique, de un modo directo, los significantes que sirven para referirse al contenido de enseñanza que es objeto de búsqueda. 
f) En cuanto a la tabulación y categorización de los datos, se aprecia una cierta diversidad en relación con los criterios utilizados para establecer las categorías, así como en la presentación de éstas en función del número de alumnos. No existe una tendencia clara con respecto a la búsqueda de relaciones entre las distintas categorías, constituyendo los intentos de jerarquización un elemento minoritario en los trabajos aparecidos a lo largo de los años.

g) Todos los trabajos utilizan como contexto teórico el que ofrece el contenido académico que es objeto de investigación, es decir, analizan las respuestas de los sujetos buscando diferencias con respecto a las que daría un experto. Algunos autores además complementan el anterior contexto con reglas y modelos relacionados con algún aspecto de la cognición del sujeto (Maloney, 1984; Bar et al., 1994). Sin embargo, no se ha encontrado ningún trabajo donde a partir de un modelo cognitivo dado se identifiquen, describan e interpreten las respuestas de los sujetos.

h) En cuanto a las estrategias de investigación utilizadas, se puede decir que existe cierta preferencia en realizar los trabajaos bajo planteamientos hipotético-deductivos frente a los inductivos, a lo largo de los años.

Nosotros pensamos que la no-aparición de nuevas concepciones en la década 1985-95, frente a la de 1975-85 (Jiménez-Gómez, Solano y Marín, 1997), se debe fundamentalmente a la escasa evolución de la metodología de investigación utilizada y, por tanto, al marco teórico que la sustenta. Análogas características metodológicas se utilizan en todos los trabajos analizados, ya sean de los años setenta, ochenta o noventa y, de las conclusiones, no se infiere una tendencia clara encaminada a abandonar o asumir nuevos modos de proceder en la búsqueda de concepciones de los alumnos a lo largo de los años, hecho que, por otro lado, ya ha sido señalado por distintos autores, como:

- Moreira (1994), en su revisión de los artículos aparecidos en los primeros diez años de la revista Enseñanza de las Ciencias, señala que más de un tercio de las investigaciones se ocupaban de las concepciones de los alumnos y que una buena parte de los mismos no tenía ninguna base teórica. Así, sostiene que realizar algunas referencias a otros autores o a determinados contextos teóricos en la introducción de los artículos, pero sin que tengan incidencia en el desarrollo posterior de los mismos, no se puede considerar como indicativo de que dichos trabajos tengan un marco teórico. Por ello, se pregunta si se debe continuar haciendo investigación en didáctica de las ciencias sin base teórica y si realmente es posible, de esta forma, hacer investigación relevante.

- Duschl (1994), director de la revista Science Education, señala que todavía se siguen enviando a su revista una gran cantidad de manuscritos sobre «concepciones», lo que constituye, desde su punto de vista, un ejemplo de dirección errónea en cuanto a la selección del problema que se va a investigar, ya que simplemente describen las concepciones de estudiantes o profesores pero no establecen vínculos con investigaciones anteriores, no hacen contribuciones claras sobre posibles direcciones futuras y no proporcionan información sobre cómo mejorar los diseños y los métodos de investigación. También apunta que ya es hora de avanzar y realizar análisis que ayuden a comprender el origen de las concepciones o las estrategias implicadas en el uso de las mismas y de abandonar las investigaciones meramente descriptivas.

- Gilbert (1995), director de la revista International Journal in Science Education, afirma que resulta sorprendente que se hayan publicado tan pocos artículos de revisión sobre lo que él denomina modelos de comprensión (refiriéndose a estudios de concepciones). Justifica este hecho en función de que, a pesar de que existan muchos conceptos para ser investigados, sólo unos pocos investigadores han publicado artículos primarios de alta calidad sobre un concepto dado y, en segundo lugar, porque, al realizarse investigaciones a corto plazo, se imposibilita el llevar a cabo auténticos estudios evolutivos, los cuales serían esenciales para poder determinar la progresión en el aprendizaje.

- Sanmartí y Azcárate (1997), directora y directora adjunta de la revista Enseñanza de las Ciencias, señalan que la mayor proporción de manuscritos que recibe la citada revista todavía se refiere más a la descripción de concepciones que a las formas de trabajar en función de las mismas y que, después de un largo período de desarrollo de investigaciones básicamente descriptivas, lo que interesa es promover trabajos interpretativos.

Según lo anterior, parece existir cierto consenso en admitir la necesidad de abandonar los estudios descriptivos sobre concepciones y en dirigir los esfuerzos hacia estudios de carácter evolutivo, que permitan conocer cómo progresa el conocimiento de los alumnos sobre un determinado contenido de enseñanza, así como en señalar la necesidad de disponer de un contexto teórico que ayude a identificar, describir e interpretar dichas concepciones

\section{REFLEXIONES ACERCA DE LOS RESUL- TADOS OBTENIDOS}

Cualquier investigación que se realice responde al modelo teórico que explícita o implícitamente tiene su autor, de tal manera que, si un investigador quiere obtener respuestas de los sujetos y analizarlas desde sus conocimientos, como experto en el contenido de ciencias objeto de investigación, puede obtener resultados diferentes a otro investigador que quiera obtener también respuestas y las analice desde un marco teórico basado en la cognición (Marín, Solano y JiménezGómez, 1996).

Si diferentes investigadores utilizan el mismo marco teórico, por ejemplo, el deducido de la propia ciencia, pero uno el de la epistemología de la ciencia y otro el de la historia, tampoco se garantiza que empleen la misma 
metodología, análogas categorías, jerarquías, interpretaciones de los datos obtenidos, etc., según se ha puesto de manifiesto en los estudios de progresión (JiménezGómez, Solano y Marín, 1997).

De lo anterior se deducen dos consideraciones a tener en cuenta:

a) Si se analizan las respuestas de los sujetos desde la perspectiva del experto en ciencias, se obtiene una información que, en la mayoría de los casos, resulta sesgada, pues se estarían considerando sólo las referidas al contenido académico y se olvidan otras de un valor didáctico igual o superior, como pueden ser las relativas a la capacidad procesual de un alumno para resolver una tarea. Además, las respuestas de los sujetos se generan en el plano cognitivo.

b) Un marco teórico estrictamente cognitivo tampoco parece ser la solución del problema, pues no se debe

\section{REFERENCIAS BIBLIOGRÁFICAS}

ABIMBOLA, I.O. (1988). The problem of terminology in the study of student conceptions in Science. Science Education, 72(2), pp. 175-184.

ACEVEDO, J.A., BOLÍVAR, J.P., LÓPEZ MOLINA, E.J. y TRUJILLO, M. (1989). Sobre las concepciones en dinámica elemental de los adolescentes formales y concretos y el cambio metodológico. Enseñanza de las Ciencias, 7(1), pp. 27-34.

BAR, V. (1989). Introducing mechanics at the elementary school. Physics Education, 24, pp. 348-352.

BAR,V.,ZINN, B., GOLDMUNTZ, R. y SNEIDER, C. (1994). Children's concepts about weight and free fall. Science Education, 78(2), pp. 149-169.

BOEHA, B.B. (1990). Aristotle, alive and well in Papua New Guinea science classrooms. Physics Education, 25, pp. 280283.

BROWN, D.E. (1989). Students' concept of force: the importance of understanding Newton's third law. Physics Education, 24 , pp. 352-358.

CARMICHAEL, P. et al. (1990). Research on students' conceptions in science: a bibliography. Children's learning in Science: University of Leeds.

CLEMENT, J., BROWN, D.E. y ZIETSMAN, A. (1989). Not all preconceptions are misconceptions: finding «anchoring conceptions» for grounding instruction on students' intuitions, International Journal of Science Education, 11, pp. 554-565. olvidar que la «ciencia del niño» es producto de la interacción del sujeto con el medio físico-natural y que el contenido objeto de enseñanza pertenece al plano de la ciencia.

Parece, por tanto, razonable, que sólo un marco teórico que tuviera en cuenta el desarrollo cognitivo del sujeto y la epistemología de la ciencia, podría constituir un marco suficientemente general y útil para investigar «lo que el alumno sabe» sobre un determinado contenido objeto de enseñanza.

\section{NOTA}

El presente trabajo ha sido financiado por la DGICYT como parte del proyecto PS93-0174 del Programa Sectorial de Promoción General del Conocimiento.
CONFREY, J. (1990). A Review of the Research on Student Conceptions in Mathematics, Science and Programming, pp. 3-56, en Cazden, C. (eds.). American Education Research Association. Michigan State University. Review of Educational Research.

DUSCHL, R.A. (1994). Editorial policy statement and introduction. Science Education, 78(3), pp. 203-208.

FINEGOLD, M. y GORSKY, P. (1991). Students' concepts of force as applied to related physical systems: A search for consistency, International Journal of Science Education, 13(1), pp. 97-113.

GALILI, I. (1993). Weight and gravity: teachers' ambiguity and students' confusion about the concepts. International Journal of Science Education, 15(2), pp. 149-162.

GALILI, I. y BAR, V. (1992). Motion implies force: where to expect vestiges of the misconception? International Journal of Science Education, 14(1), pp. 63-81.

GILBERT, J.K. (1995). Studies and fields: directions of research in Science Education. Studies in Science Education, 25, pp. 173-197.

GIORDAN, A. y DE VECHI, G. (1987). Les origenes $d u$ savoir. París: Dalachaux. Traducción cast. (1988). Los orígenes del saber. Sevilla: Díada.

GUNSTONE, R.F. y WHITE, R.T. (1981). Understanding of gravity. Science Education, 65(3), pp. 291-299.

HELM, H. (1980). Misconceptions in physics amongst South African students. Physiscs Eduaction, 15, pp. 92-105. 
HIERREZUELO, J. y MONTERO, A. (1989). La ciencia de los alumnos. Barcelona: Laia/MEC.

IVOWI, U.M.O. (1984). Misconceptions in physics amongst Nigerian secondary school students. Physics Education, 19, pp. 279-285.

JIMÉNEZ GÓMEZ, E., SOLANO, I. y MARÍN, N. (1994). Problemas de terminología en estudios realizados sobre «lo que el alumno sabe» en ciencias. Enseñanza de las Ciencias, $12(2)$, pp. 235-245.

JIMÉNEZ GÓMEZ, E., SOLANO, I. y MARÍN, N., (1997). Estudio de la progresión en la delimitación de las «ideas» del alumno sobre fuerza, Enseñanza de las Ciencias, 15(3), pp. 309-328.

KRUGER, C., PALACIO, D. y SUMMERS, M. (1992). Surveys of English Primary Teachers' Conceptions of Force, Energy and Materials. Science Education, 76(4), pp. 339-351.

KUIPER, J. y MONDLANE, E. (1994). Students' ideas of science concepts: alternative frameworks? International Journal of Science Education, 16(3), pp. 279-292.

MALONEY, D.P. (1984). Rule-governed approaches to physicsNewton's third law. Physics Education, 19, pp. 37-42.

MARÍN, N., SOLANO, I. y JIMÉNEZ GÓMEZ, E. (1996). Las ideas previas del alumno dependen del cristal con que se miran. XVII Encuentros de Didáctica de Ciencias Experimentales. La Rábida (Huelva).

MILLAR, R. (1989). Constructive criticisms. International Journal of Science Education, 11, pp. 587-596.

MONTANERO, M. y PÉREZ, A.L. (1995). A survey of students' understanding of colliding bodies. Physics Education, 30(5), pp. 277-283.

MOREIRA, M.A. (1994). Diez años de la revista Enseñanza de las Ciencias: de una ilusión a una realidad, Enseñanza de las Ciencias, 12(2), pp. 147-153.

NOCE, G., TOROSANTUCCI, G. y VICENTINI, M. (1988). The floating of objects on the moon: Prediction from a theory or experimental facts? International Journal of Science Education, 10(1), pp. 61-70.

POSNER et al. (1982). Accomodation of a Scientific Conception: Toward a Theory of Conceptual Change. Science Education. 66 , pp. 211-227.

REYNOSO, H.E., ENRIQUE FIERRO, H., GERRDO TORRES, O., VICENTINI MISSONI, M. y PÉREZ DE CELIS, J,H. (1993). The alternative frameworks presented by Mexican students and teachers concerning the free fall of bodies. International Journal of Science Education, 15(2), pp. $127-138$.

RUGGIERO, S., CARTELLI, A., DUPRE, F. y VICENTINIMISSONI, M. (1985). Weight, gravity and air pressure: Mental representations by Italian middle school pupils. European Journal of Science Education, 17(2), pp. 181194

SANMARTÍ, N. y AZCÁRATE, C. (1997). Reflexiones en torno a la línea editorial de la revista Enseñanza de las Ciencias. Enseñanza de las Ciencias, 15(1), pp. 3-9.

SELMAN, R.L., KRUPA, M.P., STONE, C.R. y JAQUETTE, D.S. (1982). Concrete operational thought and the emergence of the concept of unseen force in children's theories of electromagnetism and gravity. Science Education, 66(2), pp. 181-194.

TERRY, C. y JONES, G. (1986). Alternative frameworks: Newton's third law and conceptual change. European Journal of Science Education, 8(3), pp. 291-298.

TERRY, C., JONES, G. y HURFORD, W. (1985). Children's conceptual understanding of forces and equilibrium. Physics Education, 20, pp. 162-165.

THIJS, G.D. (1992). Evaluation of an Introductory Course on «Force» considering students' preconceptions. Science Education, 76(2), pp. 155-174.

TWIGGER, D., BYARD, M., DRIVER, R., DRAPER, S. et al. (1994). The conception of force and motion of students aged between 10 and 15 years: an interview study designed to guide instruction. International Journal of Science Education, 16(2), pp. 215-229.

VIENNOT, L. (1979). Spontaneous reasoning in elementary dynamics. European Journal of Science Education, 1(2), pp. 205-221.

VILLANI, A. y PACCA, J. (1990). Conceptos espontáneos sobre colisiones. Enseñanza de las Ciencias, 8 (3), pp. 238243.

WATTS, D.M. (1982). Gravity-don't take it for granted. Physics Education, 17, pp. 116-121.

WATTS, D.M. (1983). A study of schoolchildren's alternative frameworks of the concept of force. European Journal of Science Education, 5(2), pp. 217-230.

WATTS, D.M. y ZYLBERSZTAJN, A. (1981). A survey of some children's ideas about force. Physics Education, 16(6), pp. 360-365.

[Artículo recibido en octubre de 1997 y aceptado en enero de 1999.] 
ANEXO I

PRETENSIONES Y OBJETO DE ESTUDIO

\begin{tabular}{|c|c|c|c|}
\hline AUTORES & $\begin{array}{l}\text { PRETENSIONES } \\
\text { U OBJETIVOS DEL TRABAJO }\end{array}$ & TÉRMINOS & SIGNIFICADO \\
\hline $\begin{array}{l}\text { Viennot } \\
(1979)\end{array}$ & $\begin{array}{l}\text { Explorar y analizar el razonamiento espontáneo de } \\
\text { estudiantes en dinámica elemental. }\end{array}$ & $\begin{array}{l}\text { Razonamiento espontáneo de es- } \\
\text { tudiantes en dinámica elemental. } \\
\text { Esquema explicativo de física intui- } \\
\text { tiva. } \\
\text { Leyes intuitivas. } \\
\text { Nociones. } \\
\text { Tendencias generales en el razona- } \\
\text { miento espontáneo. } \\
\text { Ideas espontáneas. }\end{array}$ & $\begin{array}{l}\text { Razonamiento espontáneo: Representa una forma de pensamiento encontrado } \\
\text { en la conversación de cada día y en mucho de lo que uno lee, hasta el punto de } \\
\text { que cada uno de nosotros razona, de vez en cuando, de esta forma o al menos lo } \\
\text { ha hecho en alguna ocasión. Parece que puede ser formalizado en términos de } \\
\text { sus propias leyes. Esquema explicativo de física intuitiva: Representa un } \\
\text { conjunto de conceptos comunes y coherentes consigo mismos, aunque es posible } \\
\text { que sean erróneos y resisten intentos de cambio y modificación.Tiene sus } \\
\text { propias leyes y diferentes requisitos y tipos de motivación. } \\
\text { Leyes intuitivas: Son modelos que explican adecuadamente muchas respuestas } \\
\text { de los alumnos pero necesitan algunos refinamientos para tener en cuenta otras. } \\
\text { Nociones: Constituyen el centro de un modelo interpretativo que hace posible } \\
\text { predecir el probable tipo de respuesta que será dada a diferentes tipos de } \\
\text { cuestiones. Algunas son casos extremos y un estudiante particular es posible que } \\
\text { oscile entre ellos. } \\
\text { Tendencias generales en el razonamiento espontáneo: Son consecuencia de la } \\
\text { aplicación de las leyes intuitivas. } \\
\text { Ideas espontáneas de los alumnos: Predicciones de los estudiantes ante una } \\
\text { situación física. }\end{array}$ \\
\hline $\begin{array}{l}\text { Watts } \\
(1982)\end{array}$ & $\begin{array}{l}\text { Describir los esquemas alternativos de los niños } \\
\text { sobre gravedad y proporcionar a los profesores for- } \\
\text { mas útiles y rápidas de penetrar en el pensamiento de } \\
\text { los niños. }\end{array}$ & $\begin{array}{l}\text { Esquemas alternativos (en el senti- } \\
\text { do utilizado por Driver y Easley, } \\
\text { 1978). }\end{array}$ & $\begin{array}{l}\text { Son esquemas conceptuales que desarrollan los niños basados en sus propias } \\
\text { experiencias. Son muy útiles para explicar acontecimientos cotidianos, confor- } \\
\text { me ellos los ven y son persistentes al cambio. «Más que rechazar sus ideas como } \\
\text { erróneas o mal entendidas, prefiero el término de esquemas alternativos usado } \\
\text { por Driver y Easley.» (1978). } \\
\text { Cada esquema es usado más de una vez en una entrevista y por más de un alumno, } \\
\text { por lo tanto, algunos niños usan más de un esquema o ajustan sus ideas para } \\
\text { explicar o interpretar las situaciones presentadas. Estos esquemas sólo son } \\
\text { apropiados en una primera aproximación, ya que existen muchas variaciones } \\
\text { sutiles dentro de cada uno. Esto conduce a la conclusión de que para cualquier } \\
\text { grupo de alumnos sería posible que existierran tantos esquemas cualitativa- } \\
\text { mente diferentes como niños. Sin embargo, existen suficientes similitudes como } \\
\text { para justificar el conjunto de esquemas. }\end{array}$ \\
\hline $\begin{array}{l}\text { Watts } \\
(1983)\end{array}$ & $\begin{array}{l}\text { Describir las concepciones de los más jóvenes sobre } \\
\text { fuerza. }\end{array}$ & $\begin{array}{l}\text { Esquemas alternativos (en el senti- } \\
\text { do utilizado por Driver y Easley, } \\
\text { 1978). }\end{array}$ & $\begin{array}{l}\text { Un esquema alternativo puede ser considerado como los esfuerzos imaginativos } \\
\text { de una persona para describir y explicar sumundo físico. Los esquemas descritos } \\
\text { en este trabajo no proceden de un solo alumno. Se han atado cabos desde las } \\
\text { concepciones explícitas e implícitas usadas por los niños durante el curso de la } \\
\text { entrevista. Cada esquema era usado por al menos dos alumnos y usado al menos } \\
\text { dos veces durante las entrevistas. Los esquemas forman una pelicula compuesta } \\
\text { sobre ideas compartidas por un número de alumnos, enfoque llamado el «méto- } \\
\text { do mosaico» (Bloor, 1973). Se hace necesario desarrollar modelos de compren- } \\
\text { sión de los estudiantes que sean lo bastante poderosos para capturar diferencias } \\
\text { individuales importantes pero no tan específicos que el producto final sea el } \\
\text { mismo número de modelos que de alumnos. }\end{array}$ \\
\hline $\begin{array}{l}\text { Maloney } \\
(1984)\end{array}$ & $\begin{array}{l}\text { Investigar el conocimiento estratégico de los su- } \\
\text { jetos, determinando cómo los individuos se ocupan } \\
\text { de tareas específicas. }\end{array}$ & $\begin{array}{l}\text { Concepción alternativa inapropia- } \\
\text { da. } \\
\text { Regla. }\end{array}$ & $\begin{array}{l}\text { Las concepciones alternativas inapropiadas parecen ser explicaciones de los } \\
\text { individuos sobre una situación física que no son consistentes con el contenido } \\
\text { académico y son el resultado de aplicar reglas o estrategias de razonamiento. } \\
\text { El término regla es una denominación general para un modelo o estrategia de } \\
\text { razonamiento definido. }\end{array}$ \\
\hline $\begin{array}{l}\text { Terry } \\
\text { y otros } \\
(1985)\end{array}$ & $\begin{array}{l}\text { Intentar averiguar las preconcepciones intuitivas de } \\
\text { los niños sobre fuerzas y equilibrio y cualquier } \\
\text { cambio que tenga lugar en su esquema conceptual } \\
\text { como resultado de la madurez o de la instrucción. } \\
\text { Buscar estrategias que pudieran mejorar el desa- } \\
\text { rrollo conceptual en esas áreas. }\end{array}$ & $\begin{array}{l}\text { Preconcepciones intuitivas, concep- } \\
\text { ciones erróneas, creencias intuiti- } \\
\text { vas. } \\
\text { Esquema conceptual. }\end{array}$ & $\begin{array}{l}\text { Preconcepciones intuitivas, concepciones erróneas, creencias intuitivas: no da } \\
\text { definición ni se deduce una diferencia clara entre ellos. Parecen ser explicacines } \\
\text { de los alumnos sobre situaciones físicas no acordes con el contenido académico. } \\
\text { Los esquemas conceptuales parecen ser aquéllos en lo que los estudiantes basan } \\
\text { los puntos de vista que tienen sobre el mundo, que derivan de sus experiencias, } \\
\text { de lo que han leído o visto en televisión y de lo que se les ha enseñado. Dificultan } \\
\text { llegar a comprender completamente el contenido académico. }\end{array}$ \\
\hline $\begin{array}{l}\text { Ruggiero } \\
\text { y otros } \\
(1985)\end{array}$ & $\begin{array}{l}\text { Encontrar esquemas espontáneos que muestren la } \\
\text { relación entre peso, aire y gravedad. }\end{array}$ & $\begin{array}{l}\text { Esquema de comprensión, esque- } \\
\text { ma de interpretación o esquema de } \\
\text { conocimiento espontáneo. } \\
\text { Subesquema. }\end{array}$ & $\begin{array}{l}\text { El conocimiento de hechos y fenómenos usados por un niño o cualquier persona } \\
\text { sin competencia específica en un campo está organizado en esquemas o redes. } \\
\text { Los individuos construyen un esquema de comprensión mediante un enfoque } \\
\text { diferente al que utiliza la ciencia para separar y relacionar fenómenos y, aun así, } \\
\text { es científico en cuanto a que se corresponde con la experiencia y tiene poder } \\
\text { predictivo. Conocer el esquema que posee el niño permitiría anticipar las } \\
\text { respuestas de ese niño a una serie de cuestiones. } \\
\text { Dentro de cada esquema distingue una serie de subesquemas. }\end{array}$ \\
\hline $\begin{array}{l}\text { Noce y otros } \\
(1988)\end{array}$ & $\begin{array}{l}\text { Investigar si se pueden generalizar los esquemas } \\
\text { propuestos por Ruggiero (1985) extendiendo la in- } \\
\text { vestigación a otros niveles de edad tales como adul- } \\
\text { tos y niños de escuela primaria. En el caso de niños } \\
\text { de escuela primaria, averiguar si realmente tienen } \\
\text { diferentes esquemas explicativos o si sus respuestas } \\
\text { a nuestras cuestiones reflejaban su fantasía (tenden- } \\
\text { cia a dar respuestas que satisfagan a los adultos). }\end{array}$ & $\begin{array}{l}\text { Esquemas explicativos alternativos } \\
\text { o esquemas de conocimiento de } \\
\text { sentido común. } \\
\text { Creencias o concepciones. }\end{array}$ & $\begin{array}{l}\text { Esquemas explicativos alternativos o esquemas de conocimiento de sentido } \\
\text { común: son utilizados en el mismo sentido que el trabajo de Ruggiero y otros } \\
\text { (1985). } \\
\text { Creencias o concepciones: Son categorías de respuestas. Una categoría de } \\
\text { respuestas puede responder a un modelo descriptivo (respuestas que describen } \\
\text { el comportamiento de los objetos) o a un modelo explicativo (respuestas en las } \\
\text { que aparece un conjunto consistente de relaciones entre nociones y hechos). }\end{array}$ \\
\hline
\end{tabular}




\begin{tabular}{|c|c|c|c|}
\hline $\begin{array}{l}\text { Villani } \\
\text { y Pacca } \\
(1990)\end{array}$ & $\begin{array}{l}\text { Conocer los modos de pensar los procesos físicos } \\
\text { que ocurren en las colisiones. Analizar el papel que } \\
\text { juegan las interacciones recíprocas entre los cuerpos } \\
\text { en la colisión y las influencias de las simetrías } \\
\text { presentes en el problema. }\end{array}$ & $\begin{array}{l}\text { Ideas intuitivas. } \\
\text { Modelos espontáneos. }\end{array}$ & $\begin{array}{l}\text { Ideas intuitivas (no da definición). Del análisis del texto se puede deducir que } \\
\text { son ideas extraídas por el investigador a partir de las respuestas de los sujetos. } \\
\text { Estas ideas espontáneas pueden estar articuladas en modelos. } \\
\text { Modelos espontáneos. Son interpretaciones globales realizadas por el investiga- } \\
\text { dor a partir de las ideas espontáneas extraídas de las respuestas de los sujetos } \\
\text { ante una situación física. }\end{array}$ \\
\hline $\begin{array}{l}\text { Boeha } \\
(1990)\end{array}$ & $\begin{array}{l}\text { Recoger algunos puntos de vista de los estudiantes } \\
\text { parecidos a los aristotélicos en situaciones que im- } \\
\text { plican el concepto de fuerza. }\end{array}$ & Puntos de vista de los estudiantes. & $\begin{array}{l}\text { Son intentos realizados por el investigador de construir ideas o creencias que } \\
\text { puedan tener en cuenta las afirmaciones realizadas por cada estudiante, de } \\
\text { manera que esas afirmaciones sean consecuentes unas con otras. La suposición } \\
\text { de que todas las afirmaciones del estudiante son lógicamente compatibles para } \\
\text { un lector oun oyente es difícil de mantener; sin embargo, tiene que hacerse como } \\
\text { hipótesis de trabajo, ya que de otra forma sería demasiado fácil desechar } \\
\text { secciones del discurso del estudiante que parecen inconsistentes con las partes } \\
\text { que se comprenden. } \\
\text { A los puntos de vista de los estudiantes, se les ha dado una variedad de nombres } \\
\text { tales como concepciones ingenuas, creencias ingenuas, formas espontáneas de } \\
\text { razonamiento, inventarios conceptuales, conocimiento ingenuo, física intuitiva, } \\
\text { errores conceptuales, esquemas alternativos, creencias de los estudiantes, etc. }\end{array}$ \\
\hline $\begin{array}{l}\text { Thijs } \\
(1992)\end{array}$ & $\begin{array}{l}\text { Evaluar la eficacia de un curso planeado sobre fuer- } \\
\text { za en el que se tienen en cuenta las preconcepciones } \\
\text { de los estudiantes. Identificar qué estudiantes se } \\
\text { benefician del enfoque constructivista. }\end{array}$ & Concepciones erróneas. & $\begin{array}{l}\text { Son concepciones de los estudiantes, las cuales son consecuencia de que éstos } \\
\text { dan sentido al mundo construyendo significados y enlazando la nueva informa- } \\
\text { ción con la experiencia anterior y que constituyen malinterpretaciones de } \\
\text { situaciones físicas. }\end{array}$ \\
\hline $\begin{array}{l}\text { Galili } \\
\text { y Bar } \\
(1992)\end{array}$ & $\begin{array}{l}\text { Probar la hipótesis de que los fallos de comprensión } \\
\text { conceptuales sobre movimiento es posible que sobrevi- } \\
\text { van al proceso de instrucción. }\end{array}$ & $\begin{array}{l}\text { Concepciones erróneas. } \\
\text { Creencias ingenuas. }\end{array}$ & $\begin{array}{l}\text { Concepciones erróneas: Respuestas erróneas extraídas de las respuestas de los } \\
\text { sujetos cuando se les plantea una situación física particular. Algunas son } \\
\text { generalizaciones erróneas de algún postulado de la física newtoniana y otras } \\
\text { reflejan analogías con la historia de la ciencia y son considerados como puntos } \\
\text { de vista prenewtonianos. } \\
\text { Creencias ingenuas: Lo que subyace a algunas categorías de respuestas erróneas } \\
\text { o concepciones erróneas. Fueron adquiridas durante años de experiencia perso- } \\
\text { nal y por ello son más accesibles cognitivamente. }\end{array}$ \\
\hline $\begin{array}{l}\text { Reynoso } \\
\text { y otros } \\
(1993)\end{array}$ & $\begin{array}{l}\text { Analizar los diferentes esquemas relativos a la caída } \\
\text { libre que presentan los estudiantes y profesores de } \\
\text { escuelas primarias, secundarias y preuniversitarias } \\
\text { mejicanas. }\end{array}$ & $\begin{array}{l}\text { Esquemas alternativos. } \\
\text { Subesquemas alternativos. }\end{array}$ & $\begin{array}{l}\text { No los define pero dice que el procedimiento de investigación tomó como } \\
\text { referencia el desarrollado por Ruggierro y otros (1985) y Noce y otros (1988). }\end{array}$ \\
\hline $\begin{array}{l}\text { Bar } \\
\text { y otros } \\
(1994)\end{array}$ & $\begin{array}{l}\text { Identificar ideas comunes de los niños y su consis- } \\
\text { tencia, relativas a por qué caen las cosas utilizando } \\
\text { diferentes contextos. Correlacionar el desarrollo de } \\
\text { las concepciones de los niños sobre peso y caída libre } \\
\text { con sus capacidades para conservar el peso de los } \\
\text { cuerpos deformables. Verificar las ideas de los niños } \\
\text { sobre el papel de la tierra en el proceso de caída libre. }\end{array}$ & Conceptos o ideas cotidianas. & $\begin{array}{l}\text { No da definición. Parecen ser interpretaciones de las respuestas de los alumnos, } \\
\text { algo inferido de sus respuestas. }\end{array}$ \\
\hline $\begin{array}{l}\text { Twigger } \\
\text { y otros } \\
(1994)\end{array}$ & $\begin{array}{l}\text { Identificar concepciones previas comunes en el ra- } \\
\text { zonamiento de los estudiantes entre } 10-15 \text { años } \\
\text { sobre aspectos del movimiento horizontal y vertical. } \\
\text { Explorar la extensión en la cual estas concepciones } \\
\text { previas dependen de la edad. }\end{array}$ & Concepciones previas. & $\begin{array}{l}\text { No da definición. Del contexto parece deducirse que son características del } \\
\text { razonamiento de los estudiantes sobre un tópico. Son conceptualizaciones de los } \\
\text { estudiantes deducidas por el investigador a partir de las descripciones y expli- } \\
\text { caciones de los mismos. Tales conceptualizaciones llevan a los estudiantes a dar } \\
\text { respuestas incorrectas cuando se les pide explicar una situación física determi- } \\
\text { nada. Estas concepciones difieren del contenido académico y, por tanto, nece- } \\
\text { sitan ser reestructuradas para que lleguen a ser acordes con el contenido } \\
\text { académico. }\end{array}$ \\
\hline $\begin{array}{l}\text { Kuiper } \\
\text { y Mondlane } \\
\text { (1994) }\end{array}$ & $\begin{array}{l}\text { Estudiar el carácter de esquema que pueda tener la } \\
\text { comprensión de los estudiantes de fuerza. }\end{array}$ & $\begin{array}{l}\text { Esquema alternativo. } \\
\text { Idea del estudiante. }\end{array}$ & $\begin{array}{l}\text { Esquema alternativo: La comprensión del estudiante de un concepto tiene } \\
\text { carácter de esquema si muestra un conjunto de ideas mutuamente consistentes, } \\
\text { todas relativas al mismo concepto, que son usadas en diferentes áreas problema } \\
\text { y contextos. Si el estudiante tiene un esquema alternativo, cuando se le plantee } \\
\text { el mismo problema en diferentes contextos, responderá con la misma idea. } \\
\text { Ideas del estudiante: Son las unidades de comprensión del estudiante de un } \\
\text { concepto; cada idea se referirá a una situación problema, un contexto y } \\
\text { un aspecto particular del concepto. }\end{array}$ \\
\hline $\begin{array}{l}\text { Montanero } \\
\text { y Pérez } \\
(1995)\end{array}$ & $\begin{array}{l}\text { Analizar cómo explican los estudiantes las interac- } \\
\text { ciones entre dos cuerpos y qué similitudes y diferen- } \\
\text { cias se encuentran cuando se comparan con las } \\
\text { explicaciones oficiales de la dinámica clásica. Pre- } \\
\text { tende ir más allá de los aspectos puramente des- } \\
\text { criptivos al investigar las leyes que es posible que } \\
\text { los estudiantes inventen para dar origen a sus teorías } \\
\text { implícitas. }\end{array}$ & $\begin{array}{l}\text { Concepciones espontáneas. } \\
\text { Teorías implícitas o miniteorías. } \\
\text { Leyes universales. }\end{array}$ & $\begin{array}{l}\text { Concepciones espontáneas: Parecen ser descripciones de las explicaciones de } \\
\text { los alumnos sobre un cierto hecho físico. } \\
\text { Teorías implícitas: Cuando las concepciones espontáneas presentan consisten- } \\
\text { cia. Un conjunto de respuestas de los sujetos son consistentes cuando ítems } \\
\text { equivalentes (aunque con diferentes elementos perceptuales) eran respondidos } \\
\text { con la misma opción de respuesta (correcta o no). } \\
\text { Leyes universales de las teorías implícitas: Leyes que es posible que los } \\
\text { estudiantes inventen para dar origen a las teorías implícitas. }\end{array}$ \\
\hline
\end{tabular}




\section{SOBRE LA RECOGIDA DE DATOS}

\begin{tabular}{|c|c|c|c|c|}
\hline AUTORES & $\begin{array}{l}\text { CUESTIONARIO } \\
\text { DEFINITIVO }\end{array}$ & CONTEXTO & CONSTRUCCIÓN DEL CUESTIONARIO & MUESTRA \\
\hline $\begin{array}{l}\text { Viennot } \\
(1979)\end{array}$ & $\begin{array}{l}\text { Preguntas abiertas de lá- } \\
\text { piz y papel sobre situacio- } \\
\text { nes físicas presentadas. }\end{array}$ & $\begin{array}{l}\text { Situaciones físicas } \\
\text { en dibujos sacados } \\
\text { de la realidad }\end{array}$ & $\begin{array}{l}\text { Modifica las variables de las situaciones físicas presentadas. } \\
\text { Se hacen preguntas directas sobre el contenido. } \\
\text { Predecir qué ocurrirá en una determinada situación. } \\
\text { Solicita explicaciones. }\end{array}$ & $\begin{array}{l}\text { Varios cientos de estudiantes, principalmente } \\
\text { franceses, ingleses y belgas. La descripción } \\
\text { que realiza de la muestra es poco explícita. }\end{array}$ \\
\hline $\begin{array}{l}\text { Watts y } \\
\text { Zylbersztajn } \\
(1981)\end{array}$ & $\begin{array}{l}\text { Cuestionario con formato } \\
\text { de elección múltiple. Se } \\
\text { trata de elegir un dibujo } \\
\text { de los que representan las } \\
\text { fuerzas existentes. Además, } \\
\text { se pide una explicación de } \\
\text { la elección realizada. }\end{array}$ & $\begin{array}{l}\text { Situaciones físicas } \\
\text { dadas en dibujos sa- } \\
\text { cadas de la realidad. }\end{array}$ & $\begin{array}{l}\text { Se hacen preguntas directas sobre el contenido. } \\
\text { Se solicitan explicaciones. } \\
\text { Utiliza cuestiones de investigaciones anteriores. }\end{array}$ & $\begin{array}{l}125 \text { alumnos de comprehensive school y sus } \\
\text { cinco profesores. }\end{array}$ \\
\hline $\begin{array}{l}\text { Watts } \\
(1982)\end{array}$ & Entrevista sobre ejemplos. & $\begin{array}{l}\text { Situaciones físicas } \\
\text { dadas en dibujos sa- } \\
\text { cadas de la realidad. }\end{array}$ & $\begin{array}{l}\text { Se hacen preguntas directas sobre el contenido. } \\
\text { Se solicitan explicaciones. } \\
\text { Utiliza cuestiones de investigaciones anteriores. }\end{array}$ & $\begin{array}{l}20 \text { alumnos de } 1^{\circ} \text { a } 6^{\circ} \text { de escuela secundaria } \\
\text { entre } 12 \text { y } 17 \text { años de Londres. }\end{array}$ \\
\hline $\begin{array}{l}\text { Watts } \\
(1983)\end{array}$ & Entrevista sobre ejemplos. & $\begin{array}{l}\text { Situaciones físicas } \\
\text { dadas en dibujos sa- } \\
\text { cadas de la realidad. }\end{array}$ & $\begin{array}{l}\text { Se hacen preguntas directas sobre el contenido. } \\
\text { Se solicitan explicaciones. } \\
\text { Utiliza cuestiones de investigaciones anteriores. }\end{array}$ & $\begin{array}{l}20 \text { alumnos entre } 12 \text { y } 18 \text { años del área urbana } \\
\text { de Londres (junior y advanced). }\end{array}$ \\
\hline $\begin{array}{l}\text { Maloney } \\
(1984)\end{array}$ & $\begin{array}{l}\text { Test de elección mútiple y } \\
\text { además se solicita una ex- } \\
\text { plicación del procedimiento } \\
\text { seguido para completar los } \\
\text { ítems. }\end{array}$ & $\begin{array}{l}\text { Situaciones físicas en } \\
\text { dibujos sacadas de } \\
\text { la realidad. }\end{array}$ & $\begin{array}{l}\text { Se hacen preguntas directas sobre el contenido. } \\
\text { En todos los ítems se pregunta la misma cuestión. } \\
\text { Todos los ítems tienen las mismas opciones de respuesta. } \\
\text { Se solicitan explicaciones sobre el procedimiento seguido para comple- } \\
\text { tar los ítems. } \\
\text { Para la construcción del cuestionario utiliza la técnica de valoración de } \\
\text { reglas de Siegler (1976, 1978): Elige la situación más simple posible (dos } \\
\text { bloques sobre una superficie horizontal) y establece todos los tipos de } \\
\text { problemas que resultan de combinar: que los bloques estén adosados o } \\
\text { enganchados; que las masas sean iguales o distintas; que el sistema esté } \\
\text { en reposo, en movimiento con velocidad constante o con aceleración } \\
\text { constante; qué bloque es el que causa el movimiento y qué bloque se } \\
\text { opone al movimiento. } \\
\text { Cada alumno sólo contesta a cuestiones de empujar o de tirar. }\end{array}$ & $\begin{array}{l}112 \text { estudiantes de high school con distinto } \\
\text { grado de instrucción en las leyes de Newton. }\end{array}$ \\
\hline $\begin{array}{l}\text { Terry } \\
\text { y otros } \\
(1985)\end{array}$ & $\begin{array}{l}\text { Preguntas abiertas de lá- } \\
\text { piz y papel con dibujos } \\
\text { sobre situaciones físicas } \\
\text { presentadas. }\end{array}$ & $\begin{array}{l}\text { Situaciones físicas } \\
\text { dadas en dibujos sa- } \\
\text { cadas de la realidad. }\end{array}$ & $\begin{array}{l}\text { Modifica aspectos perceptivos. } \\
\text { Solicita explicaciones. } \\
\text { Se hacen preguntas directas sobre el contenido. }\end{array}$ & $\begin{array}{l}\text { Alumnos de } 3^{\circ}, 4^{\circ} \text { y } 5^{\circ} \text { año de comprehensive } \\
\text { school que habían recibido distinto nivel de } \\
\text { instrucción formal en física. }\end{array}$ \\
\hline $\begin{array}{l}\text { Ruggiero } \\
\text { y otros } \\
(1985)\end{array}$ & $\begin{array}{l}\text { Preguntas abiertas de lá- } \\
\text { piz y papel. } \\
\text { Test de elección múltiple } \\
\text { en el que se pide, además, } \\
\text { una explicación de la elec- } \\
\text { ción realizada. }\end{array}$ & $\begin{array}{l}\text { Situaciones físicas } \\
\text { dadas en dibujos sa- } \\
\text { cadas de la realidad. }\end{array}$ & $\begin{array}{l}\text { Se hacen preguntas directas sobre el contenido. } \\
\text { Solicita definiciones (peso y fuerza de gravedad). } \\
\text { Se solicitan explicaciones. } \\
\text { Utiliza cuestiones empleadas por otros investigadores. } \\
\text { Solicita al alumno que realice predicciones. } \\
\text { Construye un cuestionario definitivo que aplica a otra muestra distinta } \\
\text { después de haber ensayado dos cuestionarios anteriores. Selecciona sólo } \\
\text { algunas de las cuestiones. }\end{array}$ & $\begin{array}{l}\text { Tres muestras }\left(\mathrm{N}_{1}=22, \mathrm{~N}_{2}=8 \text { de los anteriores, }\right. \\
\mathrm{N}_{3}=40 \text { distintos de los anteriores) entre } 12-13 \\
\text { años en el último año de la escuela media } \\
\text { italiana. }\end{array}$ \\
\hline $\begin{array}{l}\text { Noce } \\
\text { y otros } \\
(1988)\end{array}$ & $\begin{array}{l}\text { Preguntas abiertas de lá- } \\
\text { piz y papel o entrevista } \\
\text { clínicautilizando fotogra- } \\
\text { fías según la muestra. }\end{array}$ & $\begin{array}{l}\text { Situaciones físicas } \\
\text { dadas en dibujos sa- } \\
\text { cadas de la realidad. }\end{array}$ & $\begin{array}{l}\text { Se hacen preguntas directas sobre el contenido. } \\
\text { Solicita predicciones al alumno. } \\
\text { Se solicitan explicaciones. } \\
\text { Solicita definiciones (de fuerza y de gravedad). } \\
\text { Utiliza cuestiones extraídas del trabajo de Ruggiero y otros (1985). }\end{array}$ & $\begin{array}{l}\text { Cinco muestras: } a \text { ) } 224 \text { estudiantes de escuela } \\
\text { secundaria, } b \text { ) } 64 \text { estudiantes universitarios de } \\
1 \text { r. año de biología, } c \text { ) } 74 \text { adultos no expertos en } \\
\text { física, } d \text { ) } 88 \text { niños de } 5^{\circ} \text { curso de escuela prima- } \\
\text { ria, } e \text { ) } 10 \text { niños entre } 8 \text { - } 12 \text { años. }\end{array}$ \\
\hline $\begin{array}{l}\text { Villani } \\
\text { y Pacca } \\
(1990)\end{array}$ & Entrevistas individuales. & $\begin{array}{l}\text { Situaciones físicas } \\
\text { dadas en dibujos sa- } \\
\text { cadas de la realidad. }\end{array}$ & $\begin{array}{l}\text { Solicita predicciones. } \\
\text { Solicita explicaciones. } \\
\text { Se hacen preguntas directas sobre el contenido. } \\
\text { Modifica variables (e implícitamente también se están variando aspectos } \\
\text { perceptivos). } \\
\text { En la entrevista, el entrevistador anotaba un resumen de las respuestas } \\
\text { del sujeto y al final se lo presentaba para que confirmara o no el registro } \\
\text { de susideas. Este procedimiento permitía volver y, por lo menos en parte, } \\
\text { evaluar sus respuestas anteriores, confirmándolas o rechazándolas. El } \\
\text { entrevistador se quedaba con la respuesta final, que sería el objeto de } \\
\text { análisis del trabajo y que presentaba, generalmente, más coherencia } \\
\text { interna que la inicial y, entonces, explicitaba mejor un conocimiento } \\
\text { articulado. }\end{array}$ & $\begin{array}{l}\text { Estudiantes que cursaban postgrado paramaestría } \\
\text { o doctorado en física teórica, experimental o } \\
\text { enseñanza de la física en el Instituto de Física } \\
\text { de la Universidad de São Paulo. Se utilizaron } \\
56 \text { en la primera parte y } 59 \text { en la segunda ( } 29 \\
\text { eran los mismos que en la primera). }\end{array}$ \\
\hline $\begin{array}{l}\text { Boeha } \\
(1990)\end{array}$ & Entrevista sobre ejemplos. & $\begin{array}{l}\text { Situaciones físicas } \\
\text { dadas en dibujos sa- } \\
\text { cadas de la realidad. }\end{array}$ & $\begin{array}{l}\text { Se hacen preguntas directas sobre el contenido. } \\
\text { Utiliza cuestiones sacadas de otras investigaciones. }\end{array}$ & $\begin{array}{l}126 \text { estudiantes de física de } 17-18 \text { años elegi- } \\
\text { dos al azar en una high school de Papua Nueva } \\
\text { Guinea. }\end{array}$ \\
\hline $\begin{array}{l}\text { Finegold } \\
\text { y Gorsky } \\
(1991)\end{array}$ & $\begin{array}{l}\text { Preguntas abiertas de lá- } \\
\text { piz y papel (en las que se } \\
\text { pedíadibujar fuerzas y nom- } \\
\text { brarlas). } \\
\text { En algunos casos también } \\
\text { se realizaban entrevistas. }\end{array}$ & $\begin{array}{l}\text { Situaciones físicas } \\
\text { en dibujos sacadas } \\
\text { de la realidad. }\end{array}$ & $\begin{array}{l}\text { Se hacen preguntas directas sobre el contenido. } \\
\text { Se solicitan explicaciones. } \\
\text { Utiliza cuestiones sacadas de otras investigaciones. } \\
\text { Se modifican variables. } \\
\text { Validez del test: Fueron usados los criterios de Ebel }(1972) \text { para evaluar } \\
\text { la validez del contenido: } a \text { ) relevancia, } b \text { ) objetividad, } c \text { ) equilibrio, } \\
d \text { ) dificultad, } e \text { ) especificidad (un test muestra especificidad si un novato } \\
\text { en el campo cubierto por el test, es generalmente incapaz de contestar }\end{array}$ & $\begin{array}{l}333 \text { estudiantes universitarios, } 144 \text { estudiantes } \\
\text { de high school (grados 11-12). (Todos habían } \\
\text { estudiado física). } 57 \text { estudiantes de high school } \\
\text { (grado 10) que no habían estudiado física. }\end{array}$ \\
\hline
\end{tabular}




\section{INVESTIGACIÓN DIDÁCTICA}

\begin{tabular}{|c|c|c|c|c|}
\hline & & & $\begin{array}{l}\text { correctamente a las cuestiones). Ebel (1972) recomienda que los prime- } \\
\text { ros cuatro criterios sean evaluados por un panel de expertos y que el } \\
\text { quinto sea evaluado sobre una base experimental. Los miembros del } \\
\text { panel ofrecieron algunas sugerencias (relacionadas con la formulación } \\
\text { de las cuestiones) que condujeron a cambios en el test. Con respecto a la } \\
\text { relevancia, objetividad, equilibrio y dificultad de la versión final del test, } \\
\text { los miembros del panel estuvieron de acuerdo con que el test cumplía las } \\
\text { especificaciones. Para evaluar la especificidad, a } 8 \text { alumnos de high } \\
\text { school inteligentes (grados 9-12) que no habían estudiado física, se les } \\
\text { pidió que cogieran el test. Se concluyó que los tests reunían los criterios } \\
\text { descritos por Ebel (1972). }\end{array}$ & \\
\hline $\begin{array}{l}\text { Thijs } \\
(1992)\end{array}$ & $\begin{array}{l}\text { Test de elección múltiple } \\
\text { en el que también se exi- } \\
\text { gían explicaciones. }\end{array}$ & $\begin{array}{l}\text { Situaciones físicas } \\
\text { en dibujos sacadas } \\
\text { de la realidad. }\end{array}$ & $\begin{array}{l}\text { Se hacen preguntas directas sobre el contenido. } \\
\text { Se solicitan explicaciones. } \\
\text { Modifica contextos. } \\
\text { El formato inicial (preguntas de lápiz y papel semicerradas en las que se } \\
\text { introducen términos sacados de investigaciones de otros autores, dejan- } \\
\text { do además la puerta abierta a otros propios del alumno y en los que se le } \\
\text { pide una explicación) fue modificado en función de los resultados } \\
\text { obtenidos. }\end{array}$ & $\begin{array}{l}\text { Diversas muestras de clases de estudiantes de } \\
15 \text { años en escuelas secundarias holandesas. El } \\
\text { estudio definitivo se hizo con } 190 \text { estudiantes } \\
\text { (15 años) de escuela secundaria holandesa. }\end{array}$ \\
\hline $\begin{array}{l}\text { Galili } \\
\text { y Bar } \\
\text { (1992) }\end{array}$ & $\begin{array}{l}\text { Preguntas abiertas de lá- } \\
\text { piz y papel sobre situacio- } \\
\text { nes físicas planteadas (di- } \\
\text { bujar fuerzas y dar una } \\
\text { explicación). }\end{array}$ & $\begin{array}{l}\text { Situaciones físicas } \\
\text { dadas en dibujos sa- } \\
\text { cados de la realidad. }\end{array}$ & $\begin{array}{l}\text { Se hacen preguntas directas sobre el contenido. } \\
\text { Algunas cuestiones son extraídas de investigaciones de otros autores. } \\
\text { Solicita explicaciones. }\end{array}$ & $\begin{array}{l}33 \text { estudiantes de } 10^{\circ} \text { grado de high school }(15 \\
\text { años) sin instrucción en dinámica; } 60 \text { de } 11^{\circ} \\
\text { grado ( } 16 \text { años) que sólo habían estudiado una } \\
\text { física estándar; } 36 \text { de } 12^{\circ} \text { grado ( } 18 \text { años); } 27 \\
\text { estudiantes desaventajados socialmente mayo- } \\
\text { res de } 23 \text { años y } 19 \text { futuros profesores mayores } \\
\text { de } 23 \text { años. }\end{array}$ \\
\hline $\begin{array}{l}\text { Reynoso } \\
\text { y otros } \\
(1993)\end{array}$ & $\begin{array}{l}\text { Preguntas abiertas de } \\
\text { lápiz y papel y entre- } \\
\text { vista personal o sólo en- } \\
\text { trevista personal para la } \\
\text { muestra de menor edad } \\
\text { (niños de primaria). }\end{array}$ & $\begin{array}{l}\text { Situaciones físicas } \\
\text { sacadas de la reali- } \\
\text { dad. }\end{array}$ & $\begin{array}{l}\text { Se piden definiciones. } \\
\text { Utiliza cuestiones de otras investigaciones. } \\
\text { Se solicitan explicaciones. } \\
\text { Se pide al alumno que prediga lo que va a ocurrir en una situación. } \\
\text { Se modifican contextos. }\end{array}$ & $\begin{array}{l}33 \text { estudiantes de primaria ( } 8-12 \text { años); } 159 \text { de } \\
\text { secundaria (11-14 años); } 111 \text { preuniversitarios } \\
\text { (16-18 años); } 19 \text { profesores de primaria y } 20 \text { de } \\
\text { preuniversitario. }\end{array}$ \\
\hline $\begin{array}{l}\text { Bar } \\
\text { y otros } \\
(1994)\end{array}$ & Entrevista clínica. & $\begin{array}{l}\text { Situaciones de las que } \\
\text { el alumno es impo- } \\
\text { sible que tenga ex- } \\
\text { periencia (expe- } \\
\text { riencias en la luna). }\end{array}$ & $\begin{array}{l}\text { Solicita explicaciones del alumno. } \\
\text { Solicita predicciones del alumno. } \\
\text { Modifica aspectos perceptivos en una de las tareas (plastilina). } \\
\text { Utiliza una tarea piagetiana. }\end{array}$ & $\begin{array}{l}400 \text { niños entre } 4 \text { y } 13 \text { años procedentes de una } \\
\text { guardería, una escuela elemental y una junior } \\
\text { high school ( } 20 \text { chicos y } 20 \text { chicas elegidos al } \\
\text { azar de cada nivel de edad). No habían recibido } \\
\text { enseñanza formal sobre peso y caída libre. }\end{array}$ \\
\hline $\begin{array}{l}\text { Twigger } \\
\text { y otros } \\
(1994)\end{array}$ & $\begin{array}{l}\text { Entrevistas de una hora en } \\
\text { parejas de alumnos. Acada } \\
\text { estudiante se le pedía es- } \\
\text { cribiro dibujar su respuesta. }\end{array}$ & $\begin{array}{l}\text { Situaciones físicas } \\
\text { reales. }\end{array}$ & $\begin{array}{l}\text { Se solicitan definiciones (fuerza). } \\
\text { Se solicitan predicciones al alumno. } \\
\text { Se solicita comprobar una predicción. } \\
\text { Se solicita explicación después de observar un hecho físico. } \\
\text { Se solicitan explicaciones. } \\
\text { Utiliza algunas cuestiones de otras investigaciones. } \\
\text { Se solicita hacer gráficos (velocidad/distancia y velocidad/tiempo). } \\
\text { Se hacen preguntas directas sobre el contenido. }\end{array}$ & 36 estudiantes (10-15 años). \\
\hline $\begin{array}{l}\text { Kuiper } \\
\text { y Mondlane } \\
\text { (1995) }\end{array}$ & $\begin{array}{l}\text { Prueba mixta de lápiz y } \\
\text { papel: opción múltiple y } \\
\text { preguntas abiertas (dibu- } \\
\text { jar fuerzas mediante fle- } \\
\text { chas y su intensidad me- } \\
\text { diante la longitud de la } \\
\text { misma y nombrarlas) para } \\
\text { explicar la elección. }\end{array}$ & $\begin{array}{l}\text { Situaciones físicas } \\
\text { sacadas de la reali- } \\
\text { dad(dibujos y vídeo). } \\
\text { Situaciones físicas } \\
\text { reales. }\end{array}$ & $\begin{array}{l}\text { Se hacen preguntas directas sobre el contenido. } \\
\text { Se solicitan explicaciones. } \\
\text { Se solicitan predicciones. } \\
\text { Utiliza alguna cuestión de otras investigaciones. } \\
\text { El mismo problema se proponía en cuatro contextos distintos (no da } \\
\text { ejemplos). }\end{array}$ & $\begin{array}{l}143 \text { alumnos de } 1^{\circ} \text { a } 6^{\circ} \text { de secundaria de } \\
\text { Zimbabue. }\end{array}$ \\
\hline $\begin{array}{l}\text { Montanero } \\
\text { y Pérez } \\
(1995)\end{array}$ & $\begin{array}{l}\text { Test de opción múltiple } \\
\text { seguido de entrevista clí- } \\
\text { nica para obtener una ex- } \\
\text { plicación de la elección. }\end{array}$ & $\begin{array}{l}\text { Situaciones físicas } \\
\text { sacadas de la reali- } \\
\text { dad (dibujos). }\end{array}$ & $\begin{array}{l}\text { Modifica contextos pero no es muy explícito al respecto, puesto que no } \\
\text { presenta el cuestionario completo. } \\
\text { Hace preguntas directas sobre el contenido. } \\
\text { Se solicitan explicaciones. } \\
\text { Se hace estudio preliminar (test de elección múltiple y explicación de la } \\
\text { respuesta escrita, entrevistas orales y discusiones de grupo) cuyo análisis } \\
\text { cualitativo sirve para elaborar hipótesis que se tendrán en cuenta para el } \\
\text { diseño del test definitivo. }\end{array}$ & $\begin{array}{l}\text { Estudio preliminar: } 40 \text { alumnos de } 16-17 \text { años. } \\
\text { Estudio definitivo: estudiantes de EGB }(78 \text { de } \\
\left.7^{\circ}, 78 \text { de } 8^{\circ}\right) \text {, de BUP }\left(72 \text { de } 2^{\circ}, 81 \text { de } 3^{\circ}\right) \text {, de } \\
\text { COU }(105) \text {, universitarios }(47 \text { de químicas }, 21 \\
\text { de física) y } 28 \text { profesores no universitarios. }\end{array}$ \\
\hline
\end{tabular}




\section{ANEXO III
ORDENACIÓN Y CATEGORIZACIÓN DE LOS DATOS}

\begin{tabular}{|c|c|c|c|}
\hline AUTORES & $\begin{array}{l}\text { AGRUPAMIENTO DE RESPUESTAS POR } \\
\text { CATEGORÍAS }\end{array}$ & CARACTERÍSTICAS DE LAS CATEGORÍAS & $\begin{array}{l}\text { CATEGORÍAS POR NÚMERO DE } \\
\text { ALUMNOS }\end{array}$ \\
\hline $\begin{array}{l}\text { Viennot } \\
\text { (1979) }\end{array}$ & $\begin{array}{l}\text { En el trabajo sólo interesa poner de manifiesto } \\
\text { cuál sería la respuesta o respuestas erróneas más } \\
\text { frecuentes dadas utilizando el razonamiento es- } \\
\text { pontáneo frente a la que correspondería a la } \\
\text { respuesta correcta desde el punto de vista acadé- } \\
\text { mico así como las leyes intuitivas, nociones y } \\
\text { tendencias generales en el razonamiento espon- } \\
\text { táneo que parecen subyacer a esas respuestas } \\
\text { erróneas. Además, un estudiante es posible que } \\
\text { oscile entre dos nociones que son casos extre- } \\
\text { mos. }\end{array}$ & $\begin{array}{l}\text { El esquema explicativo de física intuitiva tiene sus propias leyes intuiti- } \\
\text { vas, las cuales requieren algunos refinamientos que son las nociones para } \\
\text { explicar todas las respuestas de los alumnos. Las nociones utilizadas } \\
\text { dependerán de las características del problema físico planteado. }\end{array}$ & $\begin{array}{l}\text { No establece el número de alumnos para } \\
\text { las distintas categorías, puesto que lo que } \\
\text { le interesa es poner de manifiesto el razo- } \\
\text { namiento espontáneo que subyace a las } \\
\text { respuestas erróneas y puesto que el razona- } \\
\text { miento espontáneo no son sólo unos pocos } \\
\text { errores hechos por algunos estudiantes sino } \\
\text { una forma de pensamiento encontrada en la } \\
\text { conversación de cada día y en mucho de lo } \\
\text { que uno lee, hasta el punto de que cada uno } \\
\text { de nosotros razona, de vez en cuando, de } \\
\text { esta forma o, al menos, lo ha hecho en } \\
\text { alguna ocasión. }\end{array}$ \\
\hline $\begin{array}{l}\text { Watts y } \\
\text { Zylberztajn } \\
(1981)\end{array}$ & $\begin{array}{l}\text { Las categorías de respuesta son las opciones } \\
\text { elegidas. Detrás de algunas elecciones señala la } \\
\text { existencia de un esquema alternativo. }\end{array}$ & $\begin{array}{l}\text { Los esquemas alternativos inesperados encontrados o sobre los que se } \\
\text { confirmó su presencia no parecen presentar otra relación entre ellos que } \\
\text { la derivada de haber sido extraídos sobre un mismo tópico, «fuerza» en } \\
\text { distintas situaciones físicas. }\end{array}$ & $\begin{array}{l}\text { Síestablece categorías por número de alum- } \\
\text { nos, aunque en el texto sólo hace referencia } \\
\text { a las opciones mayoritarias. }\end{array}$ \\
\hline $\begin{array}{l}\text { Watts } \\
(1983)\end{array}$ & $\begin{array}{l}\text { Las categorías son los distintos esquemas alter- } \\
\text { nativos. }\end{array}$ & $\begin{array}{l}\text { Al analizar las transcripciones de las entrevistas individuales se realizó } \\
\text { un esfuerzo por construir esquemas que pudieran tener en cuenta } \\
\text { afirmaciones de un alumno de tal forma que esas afirmaciones fueran } \\
\text { compatibles con las de otro. Se ha tenido que hacer la suposición como } \\
\text { hipótesis de trabajo de que todas las afirmaciones de una persona son } \\
\text { lógicamente consistentes para un oyente o un lector. Los esquemas } \\
\text { descritos no son un continuo sino concepciones comunes a un amplio } \\
\text { grupo de estudiantes. }\end{array}$ & Es un estudio cualitativo. \\
\hline $\begin{array}{l}\text { Maloney } \\
(1984)\end{array}$ & $\begin{array}{l}\text { Cada regla (categoría) explicaría una determina- } \\
\text { da secuencia de respuestas a los ítems del test. }\end{array}$ & $\begin{array}{l}\text { Cada regla particular surge de una combinación de decisiones sobre la } \\
\text { importancia de las diferentes características de las tareas. Existiría } \\
\text { cierta jerarquía en cuanto que el rango de combinaciones posibles va } \\
\text { desde lo global, en que todas las decisiones (elección de una opción de } \\
\text { cada ítem del test) son tomadas sobre la base de la masa solamente hasta } \\
\text { lo muy particular, donde estados diferentes de movimiento son tratados } \\
\text { de forma diferente según la relación entre las masas y según sea el } \\
\text { bloque que causa el movimiento. }\end{array}$ & $\begin{array}{l}\text { Calcula el porcentaje de sujetos que utili- } \\
\text { zan las cinco reglas ( } 63 \% \text { del total) con } \\
\text { independencia del conjunto de tareas que } \\
\text { ha realizado. } \\
\text { Calcula el porcentaje de sujetos que utili- } \\
\text { zan estas cinco reglas ( } 63 \% \text { del total) en } \\
\text { función del conjunto de tareas que ha rea- } \\
\text { lizado (de empujaro de tirar) y de la base en } \\
\text { física o nivel de instrucción. } \\
\text { El pequeño número de sujetos que no die- } \\
\text { ron física en la HS impide llegar a conclu- } \\
\text { siones definitivas. } \\
\text { Compara los porcentajes de alumnos que } \\
\text { se adhieren a cada una de las reglas según } \\
\text { tuvieran o no instrucción en física indepen- } \\
\text { dientemente de si las tareas eran de empu- } \\
\text { jar o de tirar. }\end{array}$ \\
\hline $\begin{array}{l}\text { Terry } \\
\text { y otros } \\
(1985)\end{array}$ & $\begin{array}{l}\text { Solamente deduce un esquema conceptual. El } \\
\text { resto son descripciones de respuestas erróneas } \\
\text { mayoritarias para cada una de las situaciones } \\
\text { físicas propuestas. }\end{array}$ & Sólo deduce un esquema conceptual. & $\begin{array}{l}\text { Establece porcentajes mayoritarios de res- } \\
\text { puestas erróneas y correctas. No da por- } \\
\text { centajes para el único esquema conceptual } \\
\text { que deduce. }\end{array}$ \\
\hline $\begin{array}{l}\text { Ruggiero } \\
\text { y otros } \\
\text { (1985) }\end{array}$ & $\begin{array}{l}\text { Las categorías son los distintos esquemas y sub- } \\
\text { esquemas deducidos del análisis del conjunto de } \\
\text { respuestas de cada alumno a una serie de cuestio- } \\
\text { nes. }\end{array}$ & $\begin{array}{l}\text { No. Los esquemas difieren entre sí por las relaciones que se establecen } \\
\text { entre fuerza de gravedad, peso de los objetos y caída. Dentro de cada } \\
\text { esquema, los subesquemas comparten características comunes pero } \\
\text { también permiten introducir matices diferenciadores y esta diferencia- } \\
\text { ción viene determinada por el papel que se da al aire. La única jerarquía } \\
\text { existente se refiere al hecho de que existan subesquemas dentro de los } \\
\text { esquemas. }\end{array}$ & $\begin{array}{l}\text { Se hace estudio de reproducibilidad de los } \\
\text { resultados (en el que se dan porcentajes) } \\
\text { con una muestra más amplia y unos esque- } \\
\text { mas prevalecen sobre otros mientras que } \\
\text { algunos no aparecen. }\end{array}$ \\
\hline $\begin{array}{l}\text { Noce } \\
\text { y otros } \\
(1988)\end{array}$ & $\begin{array}{l}\text { Utiliza, según la muestra, las categorías de } \\
\text { Ruggiero (1985) u otras derivadas de las caracte- } \\
\text { rísticas generales de las respuestas (enfoques } \\
\text { descriptivos o explicativos). }\end{array}$ & $\begin{array}{l}\text { En cuanto a los esquemas de Ruggiero, existen subcategorías dentro de } \\
\text { cada categoría. En las muestras que éstas no son aplicables se refieren } \\
\text { a distintos enfoques para un mismo tópico que difieren en complejidad. } \\
\text { Se podría considerar que un modelo explicativo obedece a un nivel de } \\
\text { respuesta más elevado que un modelo puramente descriptivo. }\end{array}$ & $\begin{array}{l}\text { Se recogen los porcentajes de alumnos que } \\
\text { se clasifican dentro de cada una de las } \\
\text { categorías para las distintas muestras siem- } \\
\text { pre que sus respuestas estuvieran lo sufi- } \\
\text { cientemente articuladas (en el caso de los } \\
\text { individuos de menor edad). }\end{array}$ \\
\hline $\begin{array}{l}\text { Villani } \\
\text { y Pacca } \\
\text { (1990) }\end{array}$ & $\begin{array}{l}\text { Las categorías establecidas son los modelos es- } \\
\text { pontáneos para colisiones simples y para colisio- } \\
\text { nes múltiples y son establecidas cuando las ideas } \\
\text { mayoritarias que transmiten las respuestas de los } \\
\text { alumnos son interpretadas globalmente constitu- } \\
\text { yendo modelos. }\end{array}$ & $\begin{array}{l}\text { El único nexo entre los modelos es que son diferentes maneras de } \\
\text { enfocar una misma situación física y que ninguno de los modelos se } \\
\text { correspondería con la respuesta académicamente aceptada. Son todos } \\
\text { modos alternativos de pensar. }\end{array}$ & $\begin{array}{l}\text { Sólo se recogen los modelos mayoritarios } \\
\text { (modelos no correctos académicamente) y } \\
\text { no aparecen en el texto datos estadísticos. }\end{array}$ \\
\hline
\end{tabular}


INVESTIGACIÓN DIDÁCTICA

\begin{tabular}{|c|c|c|c|}
\hline $\begin{array}{l}\text { Boeha } \\
(1990)\end{array}$ & $\begin{array}{l}\text { Las categorías propuestas responden a distintos } \\
\text { aspectos de un mismo tópico, por lo que no son } \\
\text { mutuamente excluyentes y lo que tienen en co- } \\
\text { mún es que todas ellas responden a distintos } \\
\text { aspectos de una visión aristotélica de la fuerza: } \\
\text { los puntos de vista de los estudiantes han sido } \\
\text { recopilados para dar una película compuesta de } \\
\text { ideas similares a las de Aristóteles. }\end{array}$ & $\begin{array}{l}\text { El único nexo entre ellas es que corresponden a aspectos distintos del } \\
\text { mismo tópico (la visión aristotélica del movimiento). }\end{array}$ & Es un trabajo cualitativo. \\
\hline $\begin{array}{l}\text { Finegold } \\
\text { y Gorsky } \\
\text { (1991) }\end{array}$ & $\begin{array}{l}\text { Se agrupan según sean creencias, categorías con- } \\
\text { ceptuales o esquemas sobre la base de la cohe- } \\
\text { rencia o consistencia entre grupos de respuestas } \\
\text { sobre distintos sistemas físicos. }\end{array}$ & $\begin{array}{l}\text { Las distintas categorías resultantes están en relación con las distintas } \\
\text { fuerzas identificadas o no identificadas. A través de una serie de } \\
\text { preguntas se intenta relacionar el mayor número de datos posible } \\
\text { buscando consistencia o coherencia. No parecen constituir una jerar- } \\
\text { quía. }\end{array}$ & $\begin{array}{l}\text { Se calculan porcentajes de alumnos } \\
\text { que se incluyen en cada categoría } \\
\text { (creencias, categorías conceptuales o } \\
\text { esquemas). }\end{array}$ \\
\hline $\begin{array}{l}\text { Thijs } \\
(1992)\end{array}$ & $\begin{array}{l}\text { Diferencia entre situaciones de reposo y situa- } \\
\text { ciones de movimiento. Dentro de éstas, los erro- } \\
\text { res conceptuales son inferidos a partir de las } \\
\text { respuestas erróneas mayoritarias. }\end{array}$ & $\begin{array}{l}\text { Las categorías obedecen a tendencias mayoritarias inferidas de las } \\
\text { respuestas erróneas de los estudiantes. No parecen constituir ninguna } \\
\text { jerarquía. }\end{array}$ & $\begin{array}{l}\text { Sólo aparecen en el caso de porcenta- } \\
\text { je medio de alumnos que dan una } \\
\text { respuesta correcta en lugar de la con- } \\
\text { cepción errónea correspondiente y } \\
\text { compara los porcentajes medios de } \\
\text { respuestas correctas antes y después } \\
\text { de la instrucción. }\end{array}$ \\
\hline $\begin{array}{l}\text { Galili } \\
\text { y Bar } \\
(1992)\end{array}$ & $\begin{array}{l}\text { Detrás de algunas concepciones erróneas identi- } \\
\text { fica creencias ingenuas. Las concepciones erró- } \\
\text { neas suelen responder a puntos de vista pre- } \\
\text { newtonianos. }\end{array}$ & $\begin{array}{l}\text { Las concepciones erróneas dadas no son mutuamente excluyentes y } \\
\text { una respuesta de un estudiante podría contribuir a más de una categoría } \\
\text { y todas ellas parecen responder a un punto de vista prenewtoniano. } \\
\text { Algunas de ellas parecen responder a una misma creencia ingenua. Se } \\
\text { podría hablar de una cierta jerarquía en cuanto a que los estudiantes } \\
\text { sean clasificados en: grupo de los que dan la respuesta correcta, los } \\
\text { prenewtonianos y los que no responden para cada tarea. } \\
\text { En algunos casos y en relación con las concepciones erróneas, la } \\
\text { jerarquía vendría determinada por la existencia de una cierta analogía } \\
\text { histórica en los estudiantes calificados como prenewtonianos en cuan- } \\
\text { to que podrían ser ordenados a lo largo de las líneas del desarrollo } \\
\text { científico histórico. Esto está en relación con el estudio que realiza } \\
\text { utilizando muestras de distintas edades y logros académicos. }\end{array}$ & $\begin{array}{l}\text { Se recogen porcentajes de alumnos } \\
\text { que se consideran dentro de cada una } \\
\text { de las distintas categorías que se es- } \\
\text { tablecen en el trabajo. }\end{array}$ \\
\hline $\begin{array}{l}\text { Reynoso } \\
\text { y otros } \\
\text { (1993) }\end{array}$ & $\begin{array}{l}\text { El conjunto de respuestas al cuestionario de cada } \\
\text { alumno se clasifica en esquemas y subesquemas. }\end{array}$ & $\begin{array}{l}\text { La relación entre los esquemas viene determinado por los distintos } \\
\text { tratamientos que se dan a la caída de objetos en la tierra y en la luna. } \\
\text { Dentro de cada esquema son las explicaciones de los alumnos las que } \\
\text { determinan la división en subesquemas. No constituyen ninguna jerar- } \\
\text { quía; sin embargo, al realizar el estudio con distintos grupos de edad, } \\
\text { se pone de manifiesto la relevancia de los distintos esquemas y } \\
\text { subesquemas por grupos de edad. }\end{array}$ & $\begin{array}{l}\text { Se recogen los porcentajes de alum- } \\
\text { nos que se incluyen dentro de los } \\
\text { distintos esquemas y subesquemas. }\end{array}$ \\
\hline $\begin{array}{l}\text { Twigger } \\
\text { y otros } \\
(1994)\end{array}$ & $\begin{array}{l}\text { Las concepciones previas responden a distintas } \\
\text { características de la conceptuación de los estu- } \\
\text { diantes de fuerza y movimiento. }\end{array}$ & $\begin{array}{l}\text { Las categorías responden a aspectos distintos dentro de un mismo } \\
\text { tópico (fuerza y movimiento). Parece existir poca evidencia de la } \\
\text { existencia de tendencias con la edad en las concepciones de los } \\
\text { estudiantes de fuerza y movimiento. No constituyen una jerarquía. }\end{array}$ & $\begin{array}{l}\text { Se recogen porcentajes de alumnos } \\
\text { que presentan las características más } \\
\text { extendidas en cuanto a la conceptua- } \\
\text { ción de fuerza y movimiento. }\end{array}$ \\
\hline $\begin{array}{l}\text { Kuiper } \\
\text { y Mondlane } \\
\text { (1994) }\end{array}$ & $\begin{array}{l}\text { Son categorías de respuestas basadas en la dis- } \\
\text { tancia con el contenido académico. Tras un aná- } \\
\text { lisis cluster (basado en un estudio de consisten- } \\
\text { cia o coherencia) se detecta en un conjunto de } \\
\text { alumnos un esquema alternativo, no pudiendo } \\
\text { afirmarse que para los restantes grupos de edad } \\
\text { existan esquemas alternativos. }\end{array}$ & $\begin{array}{l}\text { El eje de relación es la distancia con el contenido académico. Dentro } \\
\text { de un área problema, los alumnos usan un tipo de idea consistentemen- } \\
\text { te, pero del análisis cluster se deduce que sólo el grupo de menor edad } \\
\text { parece tener un esquema alternativo mientras que los restantes parecen } \\
\text { poseer un conjunto más bien confuso de ideas sin mucha coherencia } \\
\text { lógica. Existe jerarquía en cuanto que se consideran ideas correctas, } \\
\text { intermedias e intuitivas }\end{array}$ & $\begin{array}{l}\text { Establece el número de alumnos den- } \\
\text { tro de cada categoría tanto para cada } \\
\text { tarea, en las distintas áreas problema } \\
\text { y en el análisis cluster. }\end{array}$ \\
\hline $\begin{array}{l}\text { Montanero } \\
\text { y Pérez } \\
(1995)\end{array}$ & $\begin{array}{l}\text { Sólo en el caso de los sujetos que responden } \\
\text { coherentementealconjuntodecuestionesesposible } \\
\text { determinar las leyes que utilizan para formular } \\
\text { sus teorías implícitas. }\end{array}$ & $\begin{array}{l}\text { Cada ley refleja un aspecto distinto de las colisiones. No existe } \\
\text { jerarquía en las leyes. }\end{array}$ & $\begin{array}{l}\text { Calcula porcentaje de alumnos, que } \\
\text { porniveleseducativos, responden con- } \\
\text { sistentemente al test, y éstos eran los } \\
\text { alumnos que aplicaban las leyes. }\end{array}$ \\
\hline
\end{tabular}


INVESTIGACIÓN DIDÁCTICA

\section{SECUENCIA DE LA INVESTIGACIÓN.}

\begin{tabular}{|c|c|c|}
\hline AUTORES & SUPUESTOS DE PARTIDA. HECHOS EXPLÍCITOS & METODOLOGÍA UTILIZADA \\
\hline $\begin{array}{l}\text { Viennot } \\
(1979)\end{array}$ & $\begin{array}{l}\text { Asume la existencia de esquemas explicativos espontáneos de física intuitiva, común } \\
\text { a todos los individuos. A pesar de utilizar el término piagetiano de esquema, no hace } \\
\text { referencia a ninguna teoría psicológica. }\end{array}$ & $\begin{array}{l}\text { Inductivista. Plantea preguntas sobre situaciones físicas y deduce las leyes } \\
\text { intuitivas que explican muchas respuestas de los alumnos, pero necesita } \\
\text { refinamientos para tener en cuenta otras. Para ello introduce las nociones. } \\
\text { Éstas constituyen el núcleo de un modelo interpretativo que permite predecir } \\
\text { el tipo probable de respuesta de cualquier sujeto. Además deduce tendencias } \\
\text { generales en el razonamiento espontáneo. }\end{array}$ \\
\hline $\begin{array}{l}\text { Watts } \\
(1982)\end{array}$ & $\begin{array}{l}\text { El trabajo está basado sobre dos principios: que sólo puede tener lugar una enseñanza } \\
\text { efectiva cuando esté basada sobre lo que el aprendiz ya sabe y que, si se quiere } \\
\text { averiguar lo que alguien sabe, la mejor forma es preguntárselo. Este artículo es la } \\
\text { consecuencia lógica de otros tres estudios (Nussbaum y Novak, 1976; Gunstone y } \\
\text { White, 1980; Stead y Osborne, 1979). Los niños desarrollan esquemas conceptuales } \\
\text { idiosincráticos basados en sus propias experiencias, los cuales son después usados } \\
\text { como una base para interpretar lecciones, libros, programas de televisión, etc. Estos } \\
\text { esquemas son muy útiles para explicar acontecimientos de cada día, según ellos los } \\
\text { ven, y son muy persistentes (Viennot, 1979). Más que rechazar sus ideas como } \\
\text { erróneas o mal entendidas, prefiero el término esquema alternativo usado por Driver } \\
\text { y Easley (1978). Los alumnos poseen formas de comprensión personales, por lo que } \\
\text { este trabajo se centra en este aspecto. }\end{array}$ & $\begin{array}{l}\text { Inductivista, ya que los esquemas alternativos se deducen del análisis de los } \\
\text { comentarios de los alumnos. }\end{array}$ \\
\hline $\begin{array}{l}\text { Watts } \\
(1983)\end{array}$ & $\begin{array}{l}\text { Se utiliza el término esquema alternativo cogido del trabajo de Driver y Easley (1978) } \\
\text { y puede ser definido como «los esfuerzos imaginativos de una persona para describir } \\
\text { y explicar su mundo físico». Se da a estos esquemas alternativos un estatus respetuoso, } \\
\text { que refleja su amplio uso, su coherencia interna y su tenacidad de cara a la enseñanza } \\
\text { en clase. }\end{array}$ & $\begin{array}{l}\text { Inductivista. Los esquemas alternativos son deducidos por el investigador a } \\
\text { partir de las explicaciones de los distintos alumnos. }\end{array}$ \\
\hline $\begin{array}{l}\text { Maloney } \\
(1984)\end{array}$ & $\begin{array}{l}\text { Utiliza la llamada técnica de valoración de reglas (Siegler, 1976, 1978) que es un } \\
\text { método para investigar el conocimiento estratégico de los sujetos al determinar cómo } \\
\text { los individuos se ocupan de tareas específicas. Expone una serie de consideraciones } \\
\text { derivadas de los trabajos de otros autores sobre la naturaleza y características de las } \\
\text { concepciones alternativas de los alumnos: su existencia (Towbridge y McDermott, } \\
\text { 1980; Clement, 1982; Lochhead, 1979), su persistencia a pesar de la instrucción } \\
\text { (Arons, 1982; Minstrell 1982; McDermott, 1982; Viennot, 1979; Clement, 1982; } \\
\text { McCloskey, 1980), su transformación en función de la instrucción (Gilbert et al., } \\
\text { 1982). } \\
\text { Kuhn y Phelps (1979) han afirmado que «el obstáculo más difícil al confrontar sujetos } \\
\text { no parece ser la adquisición de nuevas estrategias sino más bien la habilidad para } \\
\text { abandonar las existentes, menos adecuadas». Si esto es correcto, entonces, la identi- } \\
\text { ficación de las estrategias existentes en los estudiantes y las concepciones llegan a ser } \\
\text { extraordinariamente importantes. } \\
\text { Aunque estas estrategias alternativas son menos adecuadas en cuanto que no conducen } \\
\text { a soluciones correctas para los problemas de la tercera ley de Newton, permiten, al } \\
\text { individuo, incluso al profesor de física, dar sentido a su mundo. }\end{array}$ & $\begin{array}{l}\text { Hipotético-deductiva, ya que utiliza la «técnica de valoración de reglas de } \\
\text { Siegler», haciendo un análisis de las tareas para: } a \text { ) identificar los tipos de } \\
\text { problemas, y } b \text { ) determinar las estrategias (correctas e incorrectas) que pueden } \\
\text { ser aplicadas a las tareas sobre las cuales los sujetos van a trabajar. Después } \\
\text { de pasar el cuestionario, se contrastan las estrategias ideales con las realmente } \\
\text { utilizadas deducidas del análisis de las respuestas. }\end{array}$ \\
\hline $\begin{array}{l}\text { Terry } \\
\text { y otros } \\
(1985)\end{array}$ & $\begin{array}{l}\text { Los alumnos traen al laboratorio de física una visión del mundo que deriva de sus } \\
\text { propias experiencias de aquel mundo, de lo que ellos han leído o visto en televión y } \\
\text { de lo que han sido previamente enseñados. Muchas de las visiones que los niños } \\
\text { sostienen están basadas en preconcepciones y concepciones erróneas intuitivas de los } \\
\text { fenómenos físicos. Las concepciones erróneas dificultan a los niños a que lleguen a } \\
\text { una comprensión completa del contenido académico. } \\
\text { Hace referencias a estudios realizados por otros autores: Clement (1982), Minstrell } \\
\text { (1982). }\end{array}$ & $\begin{array}{l}\text { Inductivista. Recoge porcentajes de respuestas y a partir de algunas de ellas } \\
\text { deduce un esquema conceptual. }\end{array}$ \\
\hline $\begin{array}{l}\text { Ruggiero } \\
\text { y otros } \\
(1985)\end{array}$ & $\begin{array}{l}\text { La investigación está basada en el supuesto de que el conocimiento de hechos y } \\
\text { fenómenos usados por un niño o cualquier persona sin competencia específica en un } \\
\text { campo está organizado en esquemas o redes de relaciones, las cuales son científicas } \\
\text { en un sentido amplio de la palabra, aunque es posible que difieran de las teorías o } \\
\text { modelos reconocidos por la comunidad científica. } \\
\text { El método de analizar lo complejo en términos de sus elementos parciales es lo que } \\
\text { usualmente se llama ciencia y es lo que es presentado por profesores y libros de texto } \\
\text { como un cuerpo estructurado de conocimiento. Sin embargo, los fenómenos que esta } \\
\text { ciencia muestra como separados están siempre mezclados en la experiencia de cada } \\
\text { día. Usando el mismo tipo de metodología, una mente que esté libre de prejuicios de } \\
\text { escuela, mediante un enfoque diferente para separar y relacionar fenómenos, constru- } \\
\text { ye un esquema de comprensión que es diferente del dado por la ciencia contemporá- } \\
\text { nea, el cual es, aun así, científico respecto a que se corresponde con la experiencia y } \\
\text { tiene poder predictivo. }\end{array}$ & $\begin{array}{l}\text { Hipotético-deductiva, ya que, previa a la elaboración del cuestionario, se } \\
\text { establecen hipótesis sobre los posibles conceptos, fenómenos y relaciones que } \\
\text { se pretendía investigar. }\end{array}$ \\
\hline $\begin{array}{l}\text { Noce } \\
\text { y otros } \\
(1988)\end{array}$ & Toma como punto de partida el trabajo de Ruggiero y otros (1985). & $\begin{array}{l}\text { Hipotético-deductiva en cuanto que pretende ver si se pueden generalizar los } \\
\text { esquemas de Ruggiero y, para las muestras más jóvenes, hace previamente } \\
\text { una reflexión sobre lo que es posible que piensen, estableciendo categorías } \\
\text { a priori. }\end{array}$ \\
\hline
\end{tabular}




\begin{tabular}{|c|c|c|}
\hline $\begin{array}{l}\text { Villani } \\
\text { y Pacca } \\
(1990)\end{array}$ & $\begin{array}{l}\text { La solución formal dada por los estudiantes para problemas sobre colisiones encubre, } \\
\text { muchas veces, modos de pensar no compatibles con el formalismo matemático } \\
\text { utilizado, aunque lleve a resultados correctos. Sin embargo, ciertos problemas senci- } \\
\text { llos, pero que incluyen condiciones o factores esenciales para su comprensión, son } \\
\text { capaces de revelar modos alternativos de pensar (McDermott, 1984). }\end{array}$ & $\begin{array}{l}\text { Inductivista. Los modelos espontáneos son deducidos a partir de las respuestas } \\
\text { recogidas de los sujetos. }\end{array}$ \\
\hline $\begin{array}{l}\text { Boeha } \\
(1990)\end{array}$ & $\begin{array}{l}\text { Parece utilizar como contex to teórico explícito la historia de la ciencia en cuanto que } \\
\text { pretende recoger visiones de tipo aristotélico sostenidas por los alumnos. Además, se } \\
\text { formula como hipótesis de trabajo el que todas las afirmaciones de los estudiantes son } \\
\text { lógicamente compatibles para un lector u oyente. Además tiene en cuenta las } \\
\text { aportaciones de otros trabajos de investigación sobre el tema. }\end{array}$ & $\begin{array}{l}\text { Hipotético-deductiva en cuanto que los contenidos de las categorías estableci- } \\
\text { das están basados en distintos aspectos de la teoría aristotélica y en cuanto que } \\
\text { el autor reconoce explícitamente que tales categorías ya han sido explicitadas } \\
\text { en otras muestras por otros investigadores. }\end{array}$ \\
\hline $\begin{array}{l}\text { Finegold } \\
\text { y Gorsky } \\
\text { (1991) }\end{array}$ & $\begin{array}{l}\text { Se tienen en cuenta los datos aportados por otras investigaciones, no para apoyarse en } \\
\text { ellos sino para cuestionarlos. Coincide con Clough y Driver (1986) en la importancia } \\
\text { de la herramienta usada en la investigación en cuanto que los resultados de una } \\
\text { investigación dependen de ella: «Muchos esquemas identificados a partir de transcrip- } \\
\text { ciones de entrevistas serían presumiblemente después poco más que artefactos de la } \\
\text { metodología, soluciones transitorias inventadas en una entrevista en la que una } \\
\text { respuesta de algún tipo es un imperativo social. Se puede discutir, sin embargo, que } \\
\text { el uso de las mismas ideas intuitivas a través de contextos diferentes, pero los cuales } \\
\text { los científicos interpretan similarmente, of recerían algún apoyo para la validez de los } \\
\text { esquemas de los estudiantes como formas comúnmente útiles de pensar». De ahí la } \\
\text { importancia que le da a investigar la coherencia con la cual cada estudiante utiliza su } \\
\text { concepto de fuerza en contextos diferentes. }\end{array}$ & $\begin{array}{l}\text { Se podría decir que es en parte hipotético-deductiva en cuanto que tienen en } \\
\text { cuenta los resultados de otras investigaciones sobre el tema, no como punto de } \\
\text { partida sino para cuestionarlos. }\end{array}$ \\
\hline $\begin{array}{l}\text { Thijs } \\
(1992)\end{array}$ & $\begin{array}{l}\text { Tiene en cuenta los errores conceptuales que en el área de fuerza y movimiento han } \\
\text { sido puestos de manifiesto por investigaciones realizadas por otros autores. } \\
\text { Visión constructivista de E y A. Corriente del cambio conceptual. } \\
\text { En la visión constructivista, los estudiantes son vistos como aprendices activos, los } \\
\text { cuales dan sentido al mundo construyendo significados y enlazando nueva informa- } \\
\text { ción con la experiencia anterior. Así, el aprendizaje implica la generación y reestruc- } \\
\text { turación de las concepciones de los estudiantes (Driver y Oldham, 1986). Un proceso } \\
\text { de cambio conceptual sólo es posible que ocurra si los estudiantes están insatisfechos } \\
\text { con sus conceptos actuales y sienten la necesidad de un nuevo concepto. También, } \\
\text { según Posner y otros (1982), algunas otras condiciones tendrían que darse: los } \\
\text { estudiantes considerarán el nuevo concepto como inteligible, plausible y fructífero } \\
\text { para resolver problemas existentes. } \\
\text { Enfoques constructivistas de la enseñanza de la ciencia han sido perfilados por } \\
\text { Champagne y otros (1985a) y Driver (1989). Como dijo Driver: «Enseñar no es la } \\
\text { transmisión del conocimiento sino negociar significados. Implica la organización de } \\
\text { situaciones en la clase y el control de tareas de una forma que promueva resultados de } \\
\text { aprendizaje intencionados.» }\end{array}$ & $\begin{array}{l}\text { Inductivista, puesto que, aunque reconoce las aportaciones realizadas por otros } \\
\text { investigadores en el campo de fuerza y movimiento, considera solamente } \\
\text { aquellas malinterpretaciones deducidas del análisis de las respuestas de la } \\
\text { muestra que utiliza al estar más interesado en ver los resultados de un enfoque } \\
\text { de enseñanza basado en el cambio conceptual que en determinar concepciones } \\
\text { erróneas de los alumnos. }\end{array}$ \\
\hline $\begin{array}{l}\text { Reynoso } \\
\text { y otros } \\
(1993)\end{array}$ & $\begin{array}{l}\text { Utilizan como referencia el procedimiento de investigación desarrollado en la Univer- } \\
\text { sidad de Roma (Ruggiero et al., 1985; Noce et al., 1988). }\end{array}$ & $\begin{array}{l}\text { Inductivista en tanto que es del análisis detallado del contenido de las explica- } \\
\text { ciones de los alumnos y profesores de donde deduce los distintos esquemas y } \\
\text { subesquemas. Su principal aportación es el análisis más detallado del conteni- } \\
\text { do de los esquemas y subesquemas y el estudio de la evolución de éstos como } \\
\text { consecuencia de la incorporación del conocimiento académico. }\end{array}$ \\
\hline $\begin{array}{l}\text { Bar } \\
\text { y otros } \\
(1994)\end{array}$ & $\begin{array}{l}\text { Parten de los resultados de otros investigadores (Andersson, 1990; Piaget, 1974; } \\
\text { Minstrell, 1982; Watts, 1982) acerca del contraste entre el concepto de cada día de } \\
\text { peso y el concepto científico. Suponen que, observando a los niños sobre un amplio } \\
\text { rango de edades, es posible conocer cómo los conceptos de cada día se desarrollan } \\
\text { conforme los niños maduran. Investigan si los niños desarrollan o no estas ideas de } \\
\text { acuerdo con la «teoría de sentido común de movimiento» sugerida por Ogborn (1985). } \\
\text { Las nociones cogidas de la «teoría de sentido común de movimiento» que serán } \\
\text { aplicadas en este estudio son: soporte, pesadez y ligereza, peso como una fuerza de } \\
\text { presión, y la necesidad de un medio para transmitir fuerzas. }\end{array}$ & $\begin{array}{l}\text { Hipotético-deductiva, ya que intentan probar la utilidad de la «teoría de sentido } \\
\text { común» de Ogborn para explicar por qué las cosas caen, llegando a la } \\
\text { conclusión de que el modelo permanece aunque su apariencia cambia con la } \\
\text { edad. }\end{array}$ \\
\hline $\begin{array}{l}\text { Twigger } \\
\text { y otros } \\
(1994)\end{array}$ & $\begin{array}{l}\text { Este estudio forma parte de un proyecto de cambio conceptual en ciencias. Sostiene } \\
\text { que los estudiantes tienen concepciones previas sobre aspectos de fuerza y movimien- } \\
\text { to que difieren de la teoría newtoniana (Gunstone y Watts } 1985 \text {, McDermott 1984). }\end{array}$ & $\begin{array}{l}\text { Inductivista, puesto que las categorías empleadas son deducidas a partir de las } \\
\text { propias respuesta de los sujetos. }\end{array}$ \\
\hline $\begin{array}{l}\text { Kuiper } \\
\text { y Mondlane } \\
\text { (1994) }\end{array}$ & $\begin{array}{l}\text { Apuntan la necesidad de estudiar la presencia o ausencia del carácter de esquema en } \\
\text { la comprensión de los estudiantes, ya que de ello dependerá el que la tarea de la } \\
\text { educación sea cuestionar esos esquemas o, si no tienen esquemas, será diferente. }\end{array}$ & $\begin{array}{l}\text { Hipotético-deductiva en cuanto que, una vez definido lo que entienden por } \\
\text { esquema, realizan la investigación para ver si tales esquemas existen en el } \\
\text { razonamiento de los estudiantes. }\end{array}$ \\
\hline $\begin{array}{l}\text { Montanero } \\
\text { y Pérez } \\
(1995)\end{array}$ & $\begin{array}{l}\text { Consideran que las concepciones espontáneas de los estudiantes se agrupan en teorías } \\
\text { implícitas que poseen un cierto grado de coherencia (Claxton, 1984). }\end{array}$ & $\begin{array}{l}\text { Hipotético-deductivo en cuanto que el estudio preliminar les proporciona los } \\
\text { datos para elaborar una serie de hipótesis a tener en cuenta para el diseño del } \\
\text { test definitivo. }\end{array}$ \\
\hline
\end{tabular}

